\title{
Description and implementation of a MiXed Layer model (MXL, v1.0) for the dynamics of the atmospheric boundary layer in the Modular Earth Submodel System (MESSy)
}

\author{
R. H. H. Janssen and A. Pozzer \\ Atmospheric Chemistry Department, Max Planck Institute for Chemistry, Mainz, Germany \\ Correspondence to: R. H. H. Janssen (ruud.janssen@mpic.de) \\ Received: 8 September 2014 - Published in Geosci. Model Dev. Discuss.: 28 October 2014 \\ Revised: 27 January 2015 - Accepted: 29 January 2015 - Published: 4 March 2015
}

\begin{abstract}
We present a new submodel for the Modular Earth Submodel System (MESSy): the MiXed Layer (MXL) model for the diurnal dynamics of the convective boundary layer, including explicit representations of entrainment and surface fluxes. This submodel is embedded in a new MESSy base model (VERTICO), which represents a single atmospheric column. With the implementation of MXL in MESSy, MXL can be used in combination with other MESSy submodels that represent processes related to atmospheric chemistry. For instance, the coupling of MXL with more advanced modules for gas-phase chemistry (such as the Mainz Isoprene Mechanism 2 (MIM2)), emissions, dry deposition and organic aerosol formation than in previous versions of the MXL code is possible. Since MXL is now integrated in the MESSy framework, it can take advantage of future developments of this framework, such as the inclusion of new process submodels.

The coupling of MXL with submodels that represent other processes relevant to chemistry in the atmospheric boundary layer (ABL) yields a computationally inexpensive tool that is ideally suited for the analysis of field data, for evaluating new parametrizations for 3-D models, and for performing systematic sensitivity analyses. A case study for the DOMINO campaign in southern Spain is shown to demonstrate the use and performance of MXL/MESSy in reproducing and analysing field observations.
\end{abstract}

\section{Introduction}

In atmospheric chemistry, various types of models are used for studies on different spatio-temporal scales, ranging from box models representing a single point in space (e.g. Sander et al., 2011) to regional and global 3-D models (e.g. Jöckel et al., 2006). Here we describe the implementation of a MiXed Layer model for the dynamics of the atmospheric boundary layer (ABL) and a generic 1-D base model called VERTICO (VERTIcal COlumn) in the Modular Earth Submodel System (MESSy, Jöckel et al., 2010). The implementation of the latter is necessary because of the structure of the MESSy framework: in this framework, a base model determines the basic configuration of the coupled model, which can be a box, 1-D or 3-D model, and the individual processes are represented by base model independent process submodels that are coupled to the base model through an interface layer (Jöckel et al., 2010).

MXL represents the dynamics of the convective boundary layer at diurnal time scales with two vertically changing layers, one for the ABL and one for the free troposphere (FT). In combination with MESSy submodels that represent the other processes relevant to atmospheric chemistry, it provides a missing link between box and 3-D atmospheric chemistry models, at a spatio-temporal scale typical for measurements of atmospheric chemistry. It is especially suited for studying the diurnal evolution of chemical species that have chemical lifetimes similar to the time scales of atmospheric mixing, so for which the effects of chemistry and dynamics should be studied simultaneously (Fig. 1). Since the typical time scale of mixing of a convective boundary layer is about $15 \mathrm{~min}$, the evolution of species with a chemical time scale of min- 


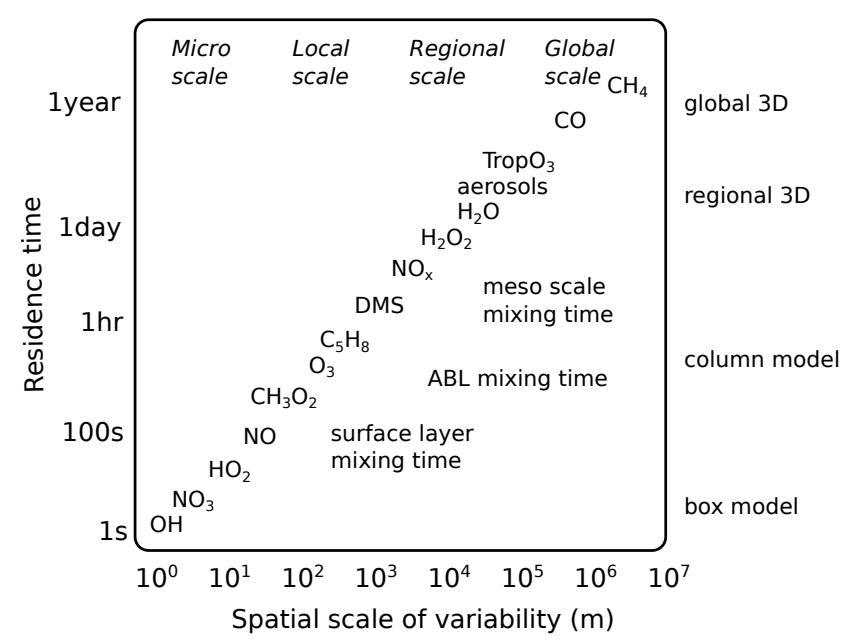

Figure 1. Spatio-temporal scales in atmospheric chemistry, typical species associated with these scales and the type of model that should be used to study their behaviour in the atmosphere.

utes to several hours (e.g. $\mathrm{O}_{3}$, isoprene, $\mathrm{NO}$ and $\mathrm{NO}_{2}$ ) will be to a similar extent driven by both dynamics and chemistry.

The MXL model was developed in the 1960s and 1970s (Lilly, 1968; Tennekes, 1973) to study the dynamics of clear and cloudy boundary layers and was first applied to atmospheric chemistry by Vilà-Guerau de Arellano et al. (2009), as MXLCH (MXL-CHemistry). Subsequently, MXLCH was applied in studies of the diurnal evolution of gas-phase chemistry (Vilà-Guerau de Arellano et al., 2011; Ouwersloot et al., 2012; Van Stratum et al., 2012) and organic aerosol (Janssen et al., 2012, 2013) in mid-latitude, tropical and boreal areas. The model explicitly accounts for entrainment (ABLFT exchange) and parametrizes turbulence in a simplified way. Although MXL uses simple parametrizations for turbulence and entrainment, the ABL dynamics as simulated by the model compare well with results from a turbulence resolving large-eddy simulation model (Pino et al., 2006) and with vertical profiles as observed from radio soundings (Ouwersloot et al., 2012).

With the implementation of MXL in MESSy (henceforth MXL/MESSy) as dynamical core and the subsequent coupling to the submodels that represent the other processes relevant to the evolution of chemical species in the troposphere, a versatile boundary layer chemistry model is created. MXL/MESSy can be used for different types of studies. First, it is well suited to supporting the interpretation of field observations in an Eulerian framework, e.g. observations from a tower. After obtaining a best fit with the observational data, a budget analysis can be performed, dividing the total tendency of species into the contributions of gasphase chemistry, ABL dynamics, emission, deposition and/or gas/particle partitioning. The chemistry term can be further subdivided into the total production and loss terms, and the contributions of individual reactions to these terms.
Secondly, MXL/MESSy is well suited for performing systematic sensitivity analyses, in which the parameter space is explored and through which non-linearities can be studied. Because it is computationally inexpensive, detailed and systematic sensitivity runs are possible. In that way, it can serve as a test bed for new parametrizations, especially in combination with a direct comparison to field data. It thus forms a link between theoretical/lab study results and 3-D model applications. Finally, it can be used in theoretical/conceptual studies, for a qualitative evaluation of feedbacks and forcings (e.g. Vilà-Guerau de Arellano et al., 2012; Janssen et al., 2012).

In Sect. 2 we describe the MXL model and give its governing equations, in Sect. 3 we focus on the implementation of the MXL model in MESSy and in Sect. 4 we show an example application of MXL/MESSy using observations from the DOMINO campaign.

\section{MXL submodel description}

The version of the MiXed Layer model that we implement here has been developed in several stages: Lilly (1968) developed the mixed-layer equations and Tennekes (1973) the turbulence closure that we apply in this work. The model for the dynamics of the convective boundary layer that resulted from this work was later coupled to an atmospheric chemistry module by Vilà-Guerau de Arellano et al. (2009) and a land surface scheme by Van Heerwaarden et al. (2009, 2010).

While the equations in this section have been published in one or more of the aforementioned references, we present here an overview of the specific and complete set of equations that are part of the implementation of MXL in MESSy. A detailed derivation of the MXL governing equations can be found in Vilà-Guerau de Arellano et al. (2015).

The mixed layer theory states that under convective conditions, strong turbulent flow, driven by the surface heat fluxes, causes perfect mixing of quantities over the entire depth of the ABL (Tennekes, 1973; Vilà-Guerau de Arellano et al., 2009, 2015). Therefore, scalars and reactants in the convective boundary layer are characterized by a well-mixed vertical profile over the whole depth of the ABL. The transition between the well-mixed ABL and the free troposphere is marked by an infinitesimally thin inversion layer. Typical profiles of potential temperature $(\theta)$, specific humidity $(q)$ and chemical species in the mixed-layer model are shown in Fig. 2. It shows that the ABL is represented by bulk values of scalars and chemical species mixing ratios, and capped by an infinitesimally thin layer over which these strongly change. Above this inversion layer lies the residual layer (the remainder of the convective boundary layer of the previous day) during the early morning and the free troposphere later during the day, which are characterized in the model by a lapse rate 


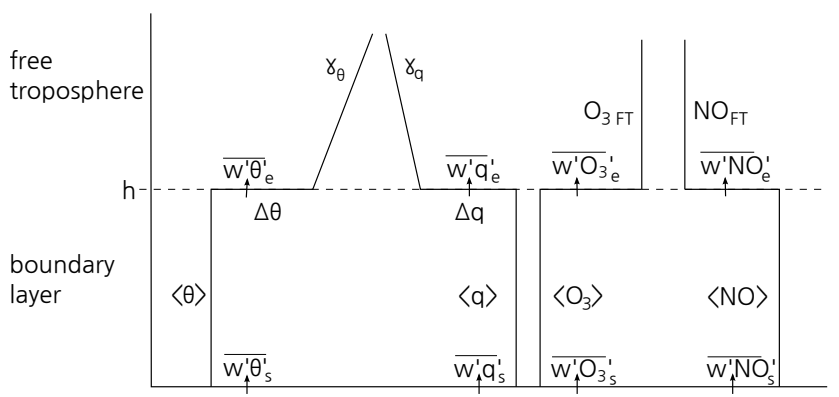

Figure 2. Typical mixed-layer profiles of potential temperature $(\theta)$, specific humidity $(q)$ and chemical species (in this case $\mathrm{O}_{3}$ and $\mathrm{NO}$ ). Also surface and entrainment fluxes of heat, moisture, $\mathrm{O}_{3}$ and $\mathrm{NO}$ are indicated; the arrows indicate the direction in which the flux is defined positively.

for heat and moisture, and a concentration profile of chemical species which is constant with height.

In addition to the local surface heat fluxes, the boundary layer dynamics can be influenced by large-scale atmospheric flows which act as external forcings on the ABL development: for instance, Janssen et al. (2013) and Pietersen et al. (2014) studied cases for which the observed ABL dynamics could only be reproduced if the influence of advection, caused by meso-scale flows, and/or subsidence, caused by a high-pressure system, were taken into account. Therefore, advection and subsidence can be prescribed as forcings to MXL.

\subsection{Governing equations for the heat budget}

The main variable in the dynamics of the convective boundary layer is the potential temperature $(\theta)$, since it is used to quantify the convective turbulence. The evolution of the potential temperature of a dry convective boundary layer is driven by the heat input at the surface (surface heat flux), at boundary layer top (entrainment heat flux) and at the lateral boundaries (advection):

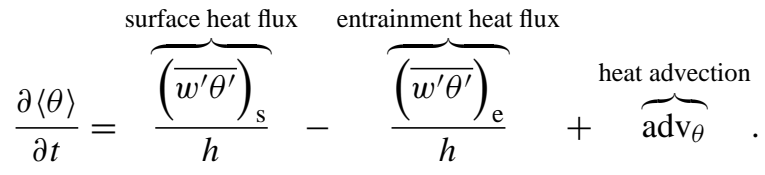

Equation (1) is the result of a vertical integration of the 1-dimensional equation of the heat budget and we have assumed that the vertical profile of $\theta$ is in quasi-steady state (Lilly, 1968), which causes a linear vertical gradient of the heat flux. In this equation, $\overline{w^{\prime} \theta^{\prime}}$ is the kinematic heat flux at the surface, which is related to the sensible heat flux (SH) as $\overline{w^{\prime} \theta^{\prime}} \mathrm{s}=\mathrm{SH} /\left(\rho \cdot c_{p}\right)$, with $\rho$ the density of air and $c_{p}$ the specific heat of air. The entrainment process, represented by $\left(\overline{w^{\prime} \theta^{\prime}}\right)$, is defined as the process whereby air from the FT is mixed into the mixed layer, and it is therefore related to the $\theta$ jump at the inversion. The evolution of $\langle\theta\rangle$ thus equals the input of heat into the $\mathrm{ABL}$ at the surface and due to entrainment over the ABL height $h$. Additionally, a heat advection term $\left(\operatorname{adv}_{\theta}\right)$, which is a large-scale forcing on the boundary layer dynamics, can be prescribed to the model.

When calculating the entrainment flux, we assume that the transition from the ABL to the FT, the inversion, is represented by a sharp discontinuity, namely the zero-order jump closure (ZOJ; Tennekes, 1973). ZOJ closure defines this jump as $\Delta \theta=\theta_{\mathrm{FT}}-\langle\theta\rangle$ over an infinitely thin inversion layer. In this ZOJ approach, the entrainment flux is the product of the entrainment velocity $w_{\mathrm{e}}$ (defined positive in the upward direction) and the potential temperature jump $\Delta \theta$ at the inversion. First-order closure approaches exist, which include the explicit representation of the depth of the entrainment zone, but the ZOJ approach already gives satisfactory results (Pino et al., 2006).

The equation for the potential temperature entrainment flux reads

$\left(\overline{w^{\prime} \theta^{\prime}}\right)_{\mathrm{e}}=-\left(\frac{\partial h}{\partial t}-w_{1}\right) \Delta \theta=-w_{\mathrm{e}} \cdot \Delta \theta$.

In our model, we calculate the subsidence velocity as

$w_{1}=-\omega h$.

where $\omega$ represents the large scale vertical velocity that is a function of the horizontal wind divergence in $\mathrm{s}^{-1}$. It can be thought of as the fraction with which the ABL is pushed down per second, due to large-scale subsiding air motions. Therefore, $w_{1}$ is per definition negative.

By rewriting Eq. (2), we obtain an expression for the boundary layer growth $\left(\frac{\partial h}{\partial t}\right)$ as a function of the entrainment flux $\left(\overline{w^{\prime} \theta^{\prime}}\right)_{\mathrm{e}}$, the potential temperature jump $(\Delta \theta)$ and the subsidence velocity $\left(w_{1}\right)$. It reads

$\frac{\partial h}{\partial t}=-\frac{\left(\overline{w^{\prime} \theta^{\prime}}\right)_{\mathrm{e}}}{\Delta \theta}+w_{1}=w_{\mathrm{e}}+w_{1}$.

This equation states that the mixed layer grows by entrainment of warm air from the free atmosphere $\left(w_{\mathrm{e}}>0\right)$ and that it is opposed by the vertical subsidence velocity $\left(w_{1}<0\right)$ driven by high pressure situations. This growth is limited by the presence of a stably stratified layer defined by a potential temperature jump on top of the convective ABL. This jump at the inversion, represented by $\Delta \theta$, changes during the growth of the mixed-layer. Consequently, depending on a positive or negative tendency of $\Delta \theta$, the ABL growth increases or decreases.

As Eq. (2) shows, the entrainment flux for heat depends on the entrainment velocity and the potential temperature jump at the inversion. It is therefore necessary to obtain a prognostic equation for the potential temperature jump. This equation reads

$$
\frac{\partial \Delta \theta}{\partial t}=\frac{\partial \theta_{\mathrm{FT}}}{\partial t}-\frac{\partial\langle\theta\rangle}{\partial t}=\gamma_{\theta}\left(\frac{\partial h}{\partial t}-w_{1}\right)-\frac{\partial\langle\theta\rangle}{\partial t},
$$


where $\gamma_{\theta}$ is the lapse rate (change with height) of $\theta$ in the FT. The final set of equations, which describes the heat budget in the diurnal atmospheric boundary layer, is therefore composed of Eqs. (1), (4) and (5). The three prognostic variables are $\langle\theta\rangle, \Delta \theta$ and $h$.

In this set of equations, four variables still remain as unknowns. The surface heat flux $\left(\overline{w^{\prime} \theta^{\prime}}\right)_{\mathrm{S}}$ is the result of landatmosphere interactions, but can be prescribed based on observations. The external variables $w_{1}$ and $\gamma_{\theta}$ represent the influence of the free tropospheric conditions on the ABL development and their values are imposed on the mixed-layer model. Finally, the entrainment heat flux $\left(\overline{w^{\prime} \theta^{\prime}}\right)$ remains. Here, we assume an important closure and we relate the entrainment flux to the surface heat flux as

$$
\left(\overline{w^{\prime} \theta^{\prime}}\right)_{\mathrm{e}}=-\beta\left(\overline{w^{\prime} \theta^{\prime}}\right)_{\mathrm{s}},
$$

where the coefficient $\beta$ can be imposed as a constant or as a parameter depending on the thermodynamic characteristics at the inversion, for instance the presence of shear (Tennekes and Driedonks, 1981; Pino et al., 2003; Conzemius and Fedorovich, 2006). In our model, we assume a value of $\beta$ equal to 0.2 (Pino et al., 2003), which physically means that the contribution of entrainment to the heat budget equals $20 \%$ of the contribution of the surface heat flux. The potential temperature is normally underestimated if this contribution is neglected. As we will show later on when introducing the moisture budget, Eq. (6) needs to be modified to make entrainment dependent on the buoyancy flux.

\subsection{Governing equations for the moisture budget}

By adding the moisture budget to the heat budget, we incorporate the effect of moisture on the buoyancy of air parcels and therewith complete the configuration of the thermodynamic variables in the ABL. The inclusion of the moisture effects on the dynamics of the $\mathrm{ABL}$ requires the introduction of two new equations. The first one (similar to Eq. 1) is the evolution of the mixed-layer specific humidity $\langle q\rangle$ :

$$
\begin{aligned}
\frac{\partial\langle q\rangle}{\partial t} & =\overbrace{\frac{\left(\overline{w^{\prime} q^{\prime}}\right)_{\mathrm{s}}}{h}}^{\text {surface moisture flux }}-\frac{\overbrace{\left(\overline{w^{\prime} q^{\prime}}\right)_{\mathrm{e}}}^{\text {entrainment moisture flux }}}{h} \\
& +\overbrace{\operatorname{adv}_{q}}^{\text {moisture advection }}
\end{aligned}
$$

where $\left(\overline{w^{\prime} q^{\prime}}\right)$ represents the surface specific moisture flux, $\left(\overline{w^{\prime} q^{\prime}}\right)_{\mathrm{e}}$ the entrainment flux of moisture and $\operatorname{adv}_{q}$ an optionally prescribed moisture advection term. The specific moisture flux is related to the latent heat flux (LE) following $\left(\overline{w^{\prime} q^{\prime}}\right)_{\mathrm{S}}=\mathrm{LE} /\left(\rho \cdot L_{\mathrm{V}}\right)$, with $L_{\mathrm{V}}$ the latent heat of vaporization. Similarly to Eq. (2), we represent the entrainment flux as

$$
\left(\overline{w^{\prime} q^{\prime}}\right)_{\mathrm{e}}=-\left(\frac{\partial h}{\partial t}-w_{1}\right) \Delta q=-w_{\mathrm{e}} \cdot \Delta q .
$$

This equation relates the dynamics of the boundary layer growth, represented by the entrainment velocity, with the specific humidity jump at the interface between the ABL and the FT.

Equation (8) requires an additional equation for the temporal evolution of the jump of $q$ at the ABL-FT interface $(\Delta q)$. It reads

$\frac{\partial \Delta q}{\partial t}=\frac{\partial q_{\mathrm{FT}}}{\partial t}-\frac{\partial\langle q\rangle}{\partial t}=\gamma_{q}\left(\frac{\partial h}{\partial t}-w_{1}\right)-\frac{\partial\langle q\rangle}{\partial t}$,

where $\gamma_{q}$ is the lapse rate of $q$ in the FT.

At this point, we need to introduce a new variable, the virtual potential temperature, which accounts for both changes in the heat and moisture budgets and is used to quantify buoyancy. It is defined as

$\theta_{\mathrm{v}}=\theta(1+0.61 q)$.

The virtual potential temperature thus accounts for the effect of water vapour on the density of air. Since moist air is less dense than dry air at the same conditions of temperature and pressure, $\theta_{\mathrm{v}}$ is always greater than the actual temperature, but only by a few degrees. The turbulent transport of this variable, the buoyancy flux, combines in one quantity the information of the potential temperature flux and the specific moisture flux. It reads

$$
\begin{aligned}
\overline{w^{\prime} \theta_{\mathrm{v}}^{\prime}} & =\overline{w^{\prime} \theta^{\prime}}+0.61\left(\langle\theta\rangle \overline{w^{\prime} q^{\prime}}+\langle q\rangle \overline{w^{\prime} \theta^{\prime}}+\overline{w^{\prime} \theta^{\prime} q^{\prime}}\right) \\
& \approx \overline{w^{\prime} \theta^{\prime}}+0.61\left(\langle\theta\rangle \overline{w^{\prime} q^{\prime}}\right) .
\end{aligned}
$$

This buoyancy flux expresses the production of turbulent kinetic energy in the ABL due to density differences. Turbulence driven by shear (mechanical turbulence) on the mixed-layer thermodynamic equations is not dealt with in our model.

The buoyancy flux directly enters in the ABL growth formulated in Eq. (2). Therefore, we rewrite Eq. (2) in the definitive form as

$\left(\overline{w^{\prime} \theta_{\mathrm{v}}^{\prime}}\right)_{\mathrm{e}}=-\left(\frac{\partial h}{\partial t}-w_{1}\right) \Delta \theta_{\mathrm{v}}=-w_{\mathrm{e}} \cdot \Delta \theta_{\mathrm{v}}$,

where $\Delta \theta_{\mathrm{v}}$ is expressed in terms of the characteristics of the $\theta$ and $q$ budgets:

$\Delta \theta_{\mathrm{v}}=\Delta \theta+0.61(\langle q\rangle \Delta \theta+\langle\theta\rangle \Delta q+\Delta \theta \Delta q)$.

By introducing the buoyancy flux as the driver of the turbulent process in the determination of the boundary layer growth, we complete the main framework of our model formulation based on mixed-layer theory.

In summary, the combined heat and moisture system is composed by the following six equations: 
1. prognostic budget equations for $\langle\theta\rangle$ and $\langle q\rangle$ (Eqs. 1 and 7),

2. boundary layer growth (Eq. 13) rewritten as

$$
\frac{\partial h}{\partial t}=-\frac{\left(\overline{w^{\prime} \theta_{\mathrm{v}}^{\prime}}\right)_{\mathrm{e}}}{\Delta \theta_{\mathrm{v}}}+w_{1},
$$

3. prognostic equations for $\Delta \theta$ and $\Delta q$ (Eqs. 5 and 9),

4. closure assumption relating the surface buoyancy flux to the entrainment buoyancy flux $\left(\overline{w^{\prime} \theta_{\mathrm{v}}^{\prime}}\right)_{\mathrm{e}}=-\beta\left(\overline{w^{\prime} \theta_{\mathrm{v}}^{\prime}}\right)_{\mathrm{s}}$.

\subsection{Governing equations for the horizontal wind budget}

As the last part of the mixed-layer dynamics, we introduce the horizontal wind, or the momentum budget (Conzemius and Fedorovich, 2006). The wind speed is important for calculating surface-atmosphere exchange, and appears for instance in the calculations of the aerodynamic resistance which governs evapotranspiration (Sect. 2.7.2) and dry deposition.

Similar expressions as for $\langle\theta\rangle$ and $\langle q\rangle$ can be used for the two horizontal components of the wind speed. These equations also contain the Coriolis force that takes into account the rotation of the Earth. This gives another four equations:

$$
\begin{aligned}
\frac{\mathrm{d}\langle u\rangle}{\mathrm{d} t} & =\frac{\left(\overline{u^{\prime} w^{\prime}}\right)_{\mathrm{s}}}{h}+\frac{\left(\overline{u^{\prime} w^{\prime}}\right)_{\mathrm{e}}}{h}-f_{\mathrm{c}} \Delta v, \\
\frac{\mathrm{d}\langle v\rangle}{\mathrm{d} t} & =\frac{\left(\overline{v^{\prime} w^{\prime}}\right)_{\mathrm{s}}}{h}+\frac{\left(\overline{v^{\prime} w^{\prime}}\right)_{\mathrm{e}}}{h}+f_{\mathrm{c}} \Delta u, \\
\frac{\mathrm{d} \Delta u}{\mathrm{~d} t} & =\gamma_{u} w_{\mathrm{e}}-\frac{\mathrm{d}\langle u\rangle}{\mathrm{d} t}, \\
\frac{\mathrm{d} \Delta v}{\mathrm{~d} t} & =\gamma_{v} w_{\mathrm{e}}-\frac{\mathrm{d}\langle v\rangle}{\mathrm{d} t},
\end{aligned}
$$

where $\langle u\rangle$ and $\langle v\rangle$ are the mixed-layer wind velocities in the $x$ and $y$ direction, $\Delta u$ and $\Delta v$ are the jumps of these two variables, $\gamma_{u}$ and $\gamma_{v}$ are the lapse rates in the FT and $f_{\mathrm{c}}$ is the Coriolis parameter. The free tropospheric wind velocities are assumed to be equal to the geostrophic wind at their height. Also for the wind budget, we assume zero-order closure:

$\overline{\left(u^{\prime} w^{\prime}\right)_{\mathrm{e}}}=-w_{\mathrm{e}} \cdot \Delta u$

$\overline{\left(v^{\prime} w^{\prime}\right)_{\mathrm{e}}}=-w_{\mathrm{e}} \cdot \Delta v$.

For applications such as in Eq. (42), $u$ and $v$ are combined to form the total horizontal wind speed:

$$
\langle U\rangle=\sqrt{\langle u\rangle^{2}+\langle v\rangle^{2}+w_{*}^{2}},
$$

where $w_{*}$ is the free convection scaling velocity:

$w_{*}=\left(\frac{g \cdot h}{\theta_{\mathrm{v}}} \overline{w^{\prime} \theta_{\mathrm{v}, \mathrm{s}}^{\prime}}\right)^{1 / 3}$.

\subsection{Governing equations for chemical species}

The mixed-layer model allows us to investigate the influence of the boundary layer dynamics on reactive atmospheric compounds during daytime. It is important to stress that in mixed-layer theory, we assume that species are mixed instantaneously as soon as they are chemically produced, emitted or entrained from the FT. In other words, the MXL model acts as a reactive chamber with the additional advantage of accounting for boundary layer growth and ABL-FT exchange.

As for scalars, the inclusion of reactive species requires the introduction of two additional equations for each species. The expression for the evolution of the generic species $C$ is similar to that for potential temperature (Eq. 1) and moisture (Eq. 7), but includes a term for the chemical transformation (Vilà-Guerau de Arellano et al., 2009):

$\frac{\partial\langle C\rangle}{\partial t}=\frac{\overbrace{\left(\overline{w^{\prime} C^{\prime}}\right)_{\mathrm{s}}}^{\text {emis./dep. flux }}}{h}-\frac{\overbrace{\left(\overline{w^{\prime} C^{\prime}}\right)_{\mathrm{e}}}^{\text {entrainment flux }}}{h}+\overbrace{S_{C}}^{\text {chemistry }}$.

By solving Eq. (24), we determine how $C$ varies over time as a function of emission/deposition processes at the surface (represented by the term $\left(\overline{w^{\prime} C^{\prime}}\right)_{\mathrm{s}}$ ), the dynamic effects ( $h$ and $\left.\left(\overline{w^{\prime} C^{\prime}}\right)_{\mathrm{e}}\right)$ and the chemical transformation $\left(S_{C}\right)$. Note that the surface fluxes of chemical species (emission or deposition) can be either prescribed (Sect. 2.5) to MXL/MESSy or calculated by other MESSy submodels (Sect. 3, Table 1). Advection of tracers is not considered, because horizontal gradients in species concentrations, which are necessary to calculate advection, are generally not constrained by observations. We are planning to implement the TNUDGE submodel (Kerkweg et al., 2006b) in the future to allow the relaxation of chemical species concentrations towards observations, which will also compensate for sources or sinks that are the result of advection of air masses with different concentrations of species.

The flux at the top of the boundary layer is represented in the same way as the entrainment flux for buoyancy, moisture and wind. For $C$ it reads

$\left(\overline{w^{\prime} C^{\prime}}\right)_{\mathrm{e}}=-w_{\mathrm{e}} \cdot \Delta C$.

By representing the exchange of $C$ as the product of the entrainment velocity and the jump of $C$, we account for both the dynamics and chemistry, which together determine the exchange between the ABL and FT.

Equation (25) requires an additional prognostic equation to solve the evolution of $\Delta C$ :

$\frac{\partial \Delta C}{\partial t}=\frac{\partial C_{\mathrm{FT}}}{\partial t}-\frac{\partial\langle C\rangle}{\partial t}$,

where $C_{\mathrm{FT}}$ is the concentration of $C$ in the FT with $\partial C_{\mathrm{FT}} / \partial t$ driven by chemical production and loss only in MXL/MESSy. 
Table 1. List of MESSy submodels coupled with MXL.

\begin{tabular}{lll}
\hline Submodel & Description & Reference \\
\hline Generic submodels & & \\
BLATHER & Standard output to log-files & Jöckel et al. (2010) \\
CHANNEL & Memory and meta-data management and data export & Jöckel et al. (2010) \\
CONSTANTS & Constants shared between submodels & Jöckel et al. (2005) \\
IMPORT & Data import from external files & www.messy-interface.org \\
SWITCH \& CONTROL & Switch and call individual submodels & Jöckel et al. (2005) \\
TIMER & Time control & Jöckel et al. (2010) \\
TOOLS & Tools shared between submodels & Jöckel et al. (2005) \\
TRACER & Management of data and meta-data of constituents & Jöckel et al. (2008) \\
\hline Process and diagnostic submodels & & \\
DDEP & Dry deposition of trace gases and aerosols & Kerkweg et al. (2006a) \\
JVAL & Photolysis rates & Sander et al. (2014) \\
MECCA & Atmospheric chemistry & Sander et al. (2011) \\
MEGAN & Emission of tracers & Guenther et al. (2006) \\
OFFEMIS (formerly OFFLEM) & Prescribed emissions of trace gases and aerosols & Kerkweg et al. (2006b) \\
ONEMIS (formerly ONLEM) & Online calculated emissions of trace gases and aerosols & Kerkweg et al. (2006b) \\
ORACLE & Organic aerosol composition and evolution & Tsimpidi et al. (2014) \\
PTRAC & Define additional prognostic tracers via namelist & Jöckel et al. (2008) \\
RADa & Radiation, heating rates & www.messy-interface.org \\
SURFACE & Surface processes & www.messy-interface.org \\
TNUDGE & Tracer nudging & Kerkweg et al. (2006b) \\
\hline
\end{tabular}

a These submodels are under development and will be implemented in the future. Currently, radiation and land surface properties are calculated as described in Sects. 2.6 and 2.7 , respectively. ${ }^{\mathrm{b}}$ To be implemented.

By assuming instantaneous mixing, we assume that the intensity of segregation of chemical species due to possible inefficient turbulent mixing is zero. It has been hypothesized that this segregation might be important for explaining model-measurement discrepancies for certain species, e.g. isoprene and the hydroxyl radical (Butler et al., 2008; Pugh et al., 2010). Later studies, however, showed that the effects of imperfect mixing are only small, with a maximum reduction of the effective rate constant for the isoprene and $\mathrm{OH}$ by less than 15\% (Ouwersloot et al., 2011; Pugh et al., 2011), and not by as much as $50 \%$, which was necessary to explain the measurement-model discrepancy. Moreover, largeeddy simulation results show well-mixed profiles throughout the convective boundary layer for species like isoprene and OH (Vilà-Guerau de Arellano et al., 2009, 2011; Ouwersloot et al., 2011) under homogeneous land surface conditions. A parametrization for the effect of the segregation of species on the effective rate constants was developed by Vinuesa and Vilà-Guerau de Arellano (2003) and can in principle be implemented to account for this effect.

\subsection{Simple emission functions}

Besides online calculation of emissions, MXL/MESSy provides the possibility to prescribe emissions, following simplified diurnal emission patterns. These include constant, sinusoidal and cosine shaped emission fluxes, respectively: $\left(\overline{w^{\prime} C^{\prime}}\right)_{\mathrm{s}}=F_{C}$,

where $F_{C}$ is the (maximum) daily emission flux $\left(\mathrm{ppb} \mathrm{m} \mathrm{s}^{-1}\right.$ ),

$\left(\overline{w^{\prime} C^{\prime}}\right)_{\mathrm{s}}=F_{C} \cdot \sin \left(\frac{\pi t}{t_{\mathrm{d}}}\right)$,

where $t$ is the time of day and $t_{\mathrm{d}}$ the day length and

$\left(\overline{w^{\prime} C^{\prime}}\right)_{\mathrm{s}}=F_{C} \cdot\left(1-\cos \left(\frac{2 \pi t}{t_{\mathrm{d}}}\right)\right)$.

For these functions, $F_{C}$ can be set by the user in the MXL namelist (an example namelist is included in the Supplement).

\subsection{Radiation model}

In this section, we describe a simple radiation model that is implemented along with MXL/MESSy. The MESSy radiation submodel RAD is intended to be implemented in the future as a second option.

The net radiation at the surface $R_{\mathrm{n}}$ is defined as the sum of the four radiation components:

$R_{\mathrm{n}}=S_{\text {in }}-S_{\text {out }}+L_{\text {in }}-L_{\text {out }}$, 
where $S_{\text {in }}$ and $S_{\text {out }}$ are the incoming and outgoing components of the short wave radiation, and $L_{\mathrm{in}}$ and $L_{\mathrm{out}}$ the incoming and outgoing component of the long wave radiation.

The incoming short wave radiation $S_{\text {in }}$ is calculated by

$S_{\text {in }}=S_{0} T_{\mathrm{r}} \sin (\Psi)$,

where $S_{\mathrm{o}}$ is the constant solar irradiance at the top of the atmosphere, set to $1365 \mathrm{~W} \mathrm{~m}^{-2}, T_{\mathrm{r}}$ the net sky transmissivity, that takes into account the influence of radiative path length and atmospheric absorption and scattering using

$T_{\mathrm{r}}=0.6+0.2 \sin (\Psi)$.

Through the solar elevation angle $\Psi$, both expressions depend on geographical location, day of the year and time of the day. $\Psi$ is calculated using

$$
\begin{aligned}
\sin (\Psi) & =\sin (\phi) \sin \left(\delta_{\mathrm{S}}\right) \\
& -\cos (\phi) \cos \left(\delta_{\mathrm{s}}\right) \cos \left(2 \pi \frac{t_{\mathrm{UTC}}}{t_{\mathrm{d}}}+\lambda_{\mathrm{e}}\right),
\end{aligned}
$$

where $t_{\mathrm{UTC}}$ is the universal time coordinate (UTC) and $t_{\mathrm{d}}$ is the diurnal period of $24 \mathrm{~h}$. The latitude $\phi$ (positive north of Equator) and longitude $\lambda_{\mathrm{e}}$ (positive east of Greenwich) define the geographic location. Variable $\delta_{\mathrm{s}}$ is the solar declination, which is a function of the day number:

$\delta_{\mathrm{s}}=\Phi_{\mathrm{r}} \cos \left(2 \pi \frac{d-d_{\mathrm{r}}}{d_{\mathrm{y}}}\right)$,

where $\Phi_{\mathrm{r}}$ is the tilt of the Earth's axis relative to the elliptic, equal to $0.409 \mathrm{rad}$. The Julian day is represented by $d$ and $d_{\mathrm{r}}$ is 173 , the day of the summer solstice. The number of days in a year $d_{\mathrm{y}}$ is set to 365 .

The outgoing shortwave radiation depends on the surface albedo:

$S_{\text {out }}=\alpha S_{\text {in }}$,

where $\alpha$ is the surface albedo.

The outgoing long wave radiation is calculated using the the Stefan-Boltzmann law:

$L_{\mathrm{out}}=\epsilon_{\mathrm{S}} \sigma_{\mathrm{SB}} T_{\mathrm{s}}^{4}$,

where $\epsilon_{\mathrm{S}}$ is the surface emissivity, set to $1, \sigma_{\mathrm{SB}}$ the StefanBoltzmann constant equal to $5.67 \times 10^{-8} \mathrm{~W} \mathrm{~m}^{-2} \mathrm{~K}^{-4}$, and $T_{\mathrm{S}}$ the surface temperature $(\mathrm{K})$.

The incoming long wave radiation is computed using the same expression, but here it uses the temperature at the top of the surface layer $T_{\mathrm{sl}}$. This temperature is acquired by converting the potential temperature of the mixed-layer $\langle\theta\rangle$ to absolute temperature using the height of surface layer top, which we define as $10 \%$ of the boundary-layer height $h$ (Jacobs and De Bruin, 1992; Van Heerwaarden et al., 2010): $z_{\mathrm{sl}}=0.1 \mathrm{~h}$. This gives the expression

$L_{\mathrm{in}}=\epsilon_{\mathrm{a}} \sigma_{\mathrm{SB}} T_{\mathrm{sl}}^{4}$,

where the atmospheric emissivity $\epsilon_{\mathrm{a}}$ is 0.8 .

\subsection{Land surface model}

A land surface model (Van Heerwaarden et al., 2009, 2010; Van Heerwaarden, 2011) is included as an option in MXL/MESSy, which enables the interactive calculation of surface heat fluxes. With this inclusion, MXL/MESSy can be used to simultaneously and interactively calculate the exchange of energy (sensible heat flux), water (latent heat flux), wind (momentum flux) and chemical species (emission and deposition) between the land surface and the ABL. In that way, a fully online coupled land surface-ABL chemistry model is obtained, in which all exchanges between the land surface and the ABL at the diurnal time scale are internal variables of the coupled system. This means that only forcings (drivers external to the system at the appropriate time scales) are prescribed to the model. These include land surface forcings (e.g. leaf area index (LAI), roughness length, soil moisture) and large-scale meteorological forcings on the ABL (e.g. incoming solar radiation, FT conditions).

\subsubsection{The surface energy balance}

The surface energy balance (SEB) forms the basis for the land surface model. It relates net radiation $R_{\mathrm{n}}$ (Eq. 30) to the surface heat fluxes:

$R_{\mathrm{n}}-G=\mathrm{SH}+\mathrm{LE}$,

where $\mathrm{SH}$ is the sensible heat flux, LE is the latent heat flux and $G$ is the ground heat flux.

The sensible and latent heat flux, which together supply the energy to the atmosphere that drives turbulent convection, are a function of land surface and atmospheric properties:

$\mathrm{SH}=\frac{\rho c_{p}}{r_{\mathrm{a}}}\left(\theta_{\mathrm{s}}-\langle\theta\rangle\right)$,
$\mathrm{LE}=\frac{\rho L_{\mathrm{v}}}{r_{\mathrm{a}}+r_{\mathrm{s}}}\left(q_{\mathrm{sat}}\left(T_{\mathrm{S}}\right)-\langle q\rangle\right)$,

where $r_{\mathrm{a}}$ is the aerodynamic resistance, $r_{\mathrm{S}}$ is the surface resistance, $\theta_{\mathrm{s}}$ and $\langle\theta\rangle$ are the potential temperatures of the surface and the mixed-layer respectively, $q_{\mathrm{sat}}\left(T_{\mathrm{S}}\right)$ is the saturated specific humidity inside the canopy and $\langle q\rangle$ is the mixed-layer specific humidity.

The Penman-Monteith equation (Monteith, 1965) is then used to relate the evaporation flux to radiation, temperature, humidity, and aerodynamic and surface resistance:

$\mathrm{LE}=\frac{\frac{\mathrm{d} q_{\mathrm{sat}}}{\mathrm{d} T}\left(R_{\mathrm{n}}-G\right)+\frac{\rho c_{p}}{r_{\mathrm{a}}}\left(q_{\mathrm{sat}}(T)-\langle q\rangle\right)}{\frac{\mathrm{d} q_{\mathrm{sat}}}{\mathrm{d} T}+\frac{c_{p}}{L_{\mathrm{v}}}\left(1+\frac{r_{\mathrm{s}}}{r_{\mathrm{a}}}\right)}$,

where $\frac{\mathrm{d} q_{\text {sat }}}{\mathrm{d} T}$, which is the slope of the saturated specific humidity curve with respect to temperature, and $q_{\text {sat }}$ are evaluated using the atmospheric mixed-layer temperature at the top of the atmospheric surface layer, defined as $10 \%$ of $h$. 


\subsubsection{Resistances}

The exchange of momentum and heat between the atmosphere with the surface is related to the strength of the turbulence. The aerodynamic resistance $r_{\mathrm{a}}$, that appears in Eqs. (39) and (40), is the inverse of this turbulent intensity and defined as

$r_{\mathrm{a}}=\frac{1}{C_{\mathrm{H}}\langle U\rangle}$,

where $C_{\mathrm{H}}$ is the drag coefficient for heat and $\langle U\rangle$ is the mixed-layer wind speed (Sect. 2.3). It shows that stronger winds lead to lower aerodynamic resistance and enhanced turbulent exchange.

The turbulent exchange also depends on the drag, which is a function of the stability of the surface layer: a growing instability in the surface layer leads to stronger convection and mixing. The drag coefficient is calculated following

$C_{\mathrm{H}}=\frac{\kappa^{2}}{A \cdot B}$

with

$A=\ln \left(\frac{z_{\mathrm{sl}}}{z_{0 \mathrm{~m}}}\right)-\Psi_{\mathrm{M}}\left(\frac{z_{\mathrm{sl}}}{L}\right)+\Psi_{\mathrm{M}}\left(\frac{z_{0 \mathrm{~m}}}{L}\right)$,

$B=\ln \left(\frac{z_{\mathrm{sl}}}{z_{0 \mathrm{~h}}}\right)-\Psi_{\mathrm{H}}\left(\frac{z_{\mathrm{sl}}}{L}\right)+\Psi_{\mathrm{H}}\left(\frac{z_{0 \mathrm{~h}}}{L}\right)$,

where $\kappa$ is the von Kármán constant, $z_{0 \mathrm{~m}}$ and $z_{0 \mathrm{~h}}$ are the roughness lengths for momentum and heat, respectively, $z_{\mathrm{sl}}$ is the depth of the atmospheric surface layer of $0.1 \mathrm{~h}, \mathrm{~L}$ is the Monin-Obukhov length and $\Psi_{\mathrm{M}}$ and $\Psi_{\mathrm{H}}$ are the integrated stability functions for momentum and heat taken from Beljaars (1991). To find the values of $L$ that are required in this function, the following implicit function is solved using a Newton-Raphson iteration method:

$$
\begin{aligned}
R i_{\mathrm{B}} & =\frac{g}{\left\langle\theta_{\mathrm{v}}\right\rangle} \frac{z_{\mathrm{sl}}\left(\left\langle\theta_{\mathrm{v}}\right\rangle-\theta_{\mathrm{v}, \mathrm{s}}\right)}{\langle U\rangle^{2}} \\
& =\frac{z_{\mathrm{sl}}}{L} \frac{\left[\ln \left(\frac{z_{\mathrm{sl}}}{z_{0 \mathrm{~h}}}\right)-\Psi_{\mathrm{H}}\left(\frac{z_{\mathrm{sl}}}{L}\right)+\Psi_{\mathrm{H}}\left(\frac{z_{0 \mathrm{~h}}}{L}\right)\right]}{\left[\ln \left(\frac{z_{\mathrm{sl}}}{z_{0 \mathrm{~m}}}\right)-\Psi_{\mathrm{M}}\left(\frac{z_{\mathrm{sl}}}{L}\right)+\Psi_{\mathrm{M}}\left(\frac{z_{0 \mathrm{~m}}}{L}\right)\right]^{2}},
\end{aligned}
$$

where $R i_{\mathrm{B}}$ is the bulk Richardson number and $\theta_{\mathrm{v}, \mathrm{s}}$ and $\left\langle\theta_{v}\right\rangle$ are the virtual potential temperatures of the surface and the mixed-layer atmosphere respectively.

The calculations of both resistances $r_{\mathrm{veg}}$ and $r_{\text {soil }}$ follow the method of Jarvis (1976) and are employed similarly as in the ECMWF global forecasting model. The vegetation resistance is based on the following multiplicative equation.

$r_{\mathrm{veg}}=\frac{r_{\mathrm{s}, \mathrm{min}}}{\mathrm{LAI}} f_{1}\left(S_{\mathrm{in}}\right) f_{2}\left(w_{2}\right) f_{3}(\mathrm{VPD}) f_{4}(T)$,

where $r_{\mathrm{s} \text {, min }}$ is the minimum surface resistance, LAI the leaf area index of the vegetated fraction, $f_{1}$ a correction function depending on incoming short wave radiation $S_{\text {in }}, f_{2}$ a function depending on soil moisture $w, f_{3}$ a function depending on vapour pressure deficit (VPD) and $f_{4}$ a function depending on temperature $T$. Of these correction functions, the first three originate from the ECMWF model documentation and the fourth from Noilhan and Planton (1989) and are defined as

$$
\begin{aligned}
& \frac{1}{f_{1}\left(S_{\text {in }}\right)}=\min \left(1, \frac{0.004 S_{\text {in }}+0.05}{0.81\left(0.004 S_{\text {in }}+1\right)}\right) \\
& \frac{1}{f_{2}(w)}=\frac{w-w_{\text {wilt }}}{w_{\text {fc }}-w_{\text {wilt }}} \\
& \frac{1}{f_{3}(\mathrm{VPD})}=\exp \left(g_{\mathrm{D}} \mathrm{VPD}\right) \\
& \frac{1}{f_{4}(T)}=1.0-0.0016(298.0-T)^{2},
\end{aligned}
$$

where $w_{\text {wilt }}$ is the volumetric soil moisture at wilting point, $w_{\mathrm{fc}}$ is the volumetric soil moisture at field capacity and $g_{\mathrm{D}}$ is a correction factor for vapour pressure deficit that only plays a role in high vegetation.

The soil resistance depends on the amount of soil moisture in the layer that has direct contact with the atmosphere.

$r_{\mathrm{soil}}=r_{\mathrm{s}, \min } f_{2}\left(w_{1}\right)$,

where $f_{2}$ is calculated following Eq. (47).

\subsubsection{Evapotranspiration calculation}

The total evapotranspiration consists of three parts: soil evaporation, leaf transpiration and evaporation of liquid water from the leaf surface. The total evapotranspiration is therefore proportional to the vegetated fraction of the land surface:

$$
\begin{aligned}
\mathrm{LE} & =c_{\mathrm{veg}}\left(1-c_{\mathrm{liq}}\right) \mathrm{LE}_{\mathrm{veg}}+c_{\mathrm{veg}} c_{\mathrm{liq}} \mathrm{LE}_{\mathrm{liq}} \\
& +\left(1-c_{\mathrm{veg}}\right) \mathrm{LE}_{\mathrm{soil}},
\end{aligned}
$$

where $\mathrm{LE}_{\mathrm{veg}}$ is the transpiration from vegetation, $\mathrm{LE}_{\text {soil }}$ the evaporation from the soil and $\mathrm{LE}_{\text {liq }}$ the evaporation of liquid water. The fractions that are used are $c_{\mathrm{veg}}$, which is the fraction of the total area that is covered by vegetation and $c_{\text {liq }}$, which is the fraction of the vegetated area that contains liquid water. Since $c_{\text {liq }}$ is not constant in time, it is modelled following

$c_{\text {liq }}=\frac{W_{1}}{\mathrm{LAI} W_{\max }}$,

where $W_{\max }$ is the representative depth of a water layer that can lay on one leaf and $W_{1}$ the actual water depth. The evolution of $W_{1}$ is governed by the following equation:

$\frac{\mathrm{d} W_{1}}{\mathrm{~d} t}=\frac{\mathrm{LE}}{\rho_{\mathrm{w}} L_{\mathrm{v}}}$,

where $\rho_{\mathrm{w}}$ is the density of water. 


\subsubsection{Soil model}

A soil model is available for the calculation of soil temperature and moisture changes that occur on diurnal time scales, and therefore affect the surface heat fluxes. It is a forcerestore soil model, based on the model formulation of Noilhan and Planton (1989) with the soil temperature formulation from Duynkerke (1991). The soil model consists of two layers, of which only the thin upper layer follows a diurnal cycle. The soil temperature in the upper layer $\left(T_{\text {soil1 }}\right)$ is calculated using the following equation, where the first term is the force term and the second the restore term:

$\frac{\mathrm{d} T_{\text {soil1 }}}{\mathrm{d} t}=C_{\mathrm{T}} G-\frac{2 \pi}{\tau}\left(T_{\text {soil1 }}-T_{\text {soil2 }}\right)$,

where $C_{\mathrm{T}}$ is the surface soil/vegetation heat capacity, $G$ the soil heat flux already introduced in the SEB, $\tau$ the time constant of one day and $T_{\text {soil } 2}$ the temperature of the deeper soil layer. The soil heat flux is calculated using

$G=\Lambda\left(T_{\mathrm{s}}-T_{\mathrm{soil1}}\right)$,

where $\Lambda$ is the thermal conductivity of the skin layer. The heat capacity $C_{\mathrm{T}}$ is calculated following Clapp and Hornberger (1978) using

$C_{\mathrm{T}}=C_{\mathrm{T}, \mathrm{sat}}\left(\frac{w_{\mathrm{sat}}}{w_{2}}\right)^{b / 2 \log 10}$,

where $C_{\mathrm{T} \text {,sat }}$ is the soil heat capacity at saturation, $w_{2}$ the volumetric water content of the deeper soil layer and $b$ an empirical constant that originates from data fitting.

The evolution of the volumetric water content of the top soil layer $w_{1}$ is calculated using

$\frac{\mathrm{d} w_{1}}{\mathrm{~d} t}=-\frac{C_{1}}{\rho_{\mathrm{W}} d_{1}} \frac{\mathrm{LE}_{\mathrm{soil}}}{L_{\mathrm{v}}}-\frac{C_{2}}{\tau}\left(w_{1}-w_{1, \mathrm{eq}}\right)$,

where $w_{1, \text { eq }}$ is the water content of the top soil layer in equilibrium, $d_{1}$ is a normalization depth and where $C_{1}$ and $C_{2}$ are two coefficients related to the Clapp and Hornberger parametrization (Clapp and Hornberger, 1978), that are calculated using

$C_{1}=C_{1, \mathrm{sat}}\left(\frac{w_{\mathrm{sat}}}{w_{1}}\right)^{b / 2+1}$

$C_{2}=C_{2, \text { ref }} \frac{w_{2}}{w_{\text {sat }}-w_{2}}$,

where $C_{1 \text {,sat }}$ and $C_{2 \text {,ref }}$ are constants taken from Clapp and Hornberger (1978). The water content of the top soil layer in equilibrium is

$w_{1, \text { eq }}=w_{2}-w_{\text {sat }} a\left(\frac{w_{2}}{w_{\text {sat }}}\right)^{p}\left(1-\left(\frac{w_{2}}{w_{\text {sat }}}\right)^{8 p}\right)$

with $a$ and $p$ two more fitted constants from Clapp and Hornberger (1978).

\subsubsection{Surface fluxes of momentum}

Finally, we introduce parametrizations for the momentum fluxes at the surface (Stull, 1988) and the friction velocity $\left(u_{*}\right)$, which are required to calculate the horizontal wind budget in the mixed layer (Sect. 2.3).

$u_{*}=\sqrt{C_{\mathrm{M}}}\langle U\rangle$,

$\overline{u^{\prime} w^{\prime}}{ }_{\mathrm{s}}=-C_{\mathrm{M}}\langle U\rangle\langle u\rangle$,

$\overline{v^{\prime} w_{\mathrm{s}}^{\prime}}=-C_{\mathrm{M}}\langle U\rangle\langle v\rangle$,

where $C_{\mathrm{M}}$ is the drag coefficient for momentum, defined as

$C_{\mathrm{M}}=\frac{\kappa^{2}}{\left[\ln \left(\frac{z_{\mathrm{sl}}}{z_{0 \mathrm{~m}}}\right)-\Psi_{\mathrm{M}}\left(\frac{z_{\mathrm{sl}}}{L}\right)+\Psi_{\mathrm{M}}\left(\frac{z_{0 \mathrm{~m}}}{L}\right)\right]}$.

\section{Implementation in the MESSy structure}

MESSy is an interface to couple submodels of earth system processes, which offers great flexibility to choose between different geophysical and -chemical processes. In the first version of MESSy, only the general circulation model ECHAM5 could be used (Jöckel et al., 2005). The second round of development also enabled the use of base models with different dimensions (Jöckel et al., 2010). For the current implementation, we used MESSy version 2.50.

Here, we give a brief overview of the MESSy structure, more details can be found in Jöckel et al. (2005, 2010). In MESSy, each FORTRAN module belongs to one of the following layers:

- The Base Model Layer (BML) defines the domain of the model, which can be a box, 1-D or 3-D. This can be a complex atmospheric model, for instance a general circulation model like ECHAM5 (Jöckel et al., 2005), but in our case it consists of two boxes stacked on top of each other (Fig. 3).

- The Base Model Interface Layer (BMIL) manages the calls to specific submodels, data input and output, and data transfer between the submodels and the base model. Global variables are stored in structures called "channel objects".

- The SubModel Interface Layer (SMIL) collects relevant data from the BMIL, transfers it to the SMCL and sends the calculated results back to the BMIL. The SMIL contains the calls of the respective submodel routines for the initialization, time integration, and finalizing phase of the model.

- The SubModel Core Layer (SMCL) contains the code for the base model-independent implementation of the physical and chemical processes or a diagnostic tool. 


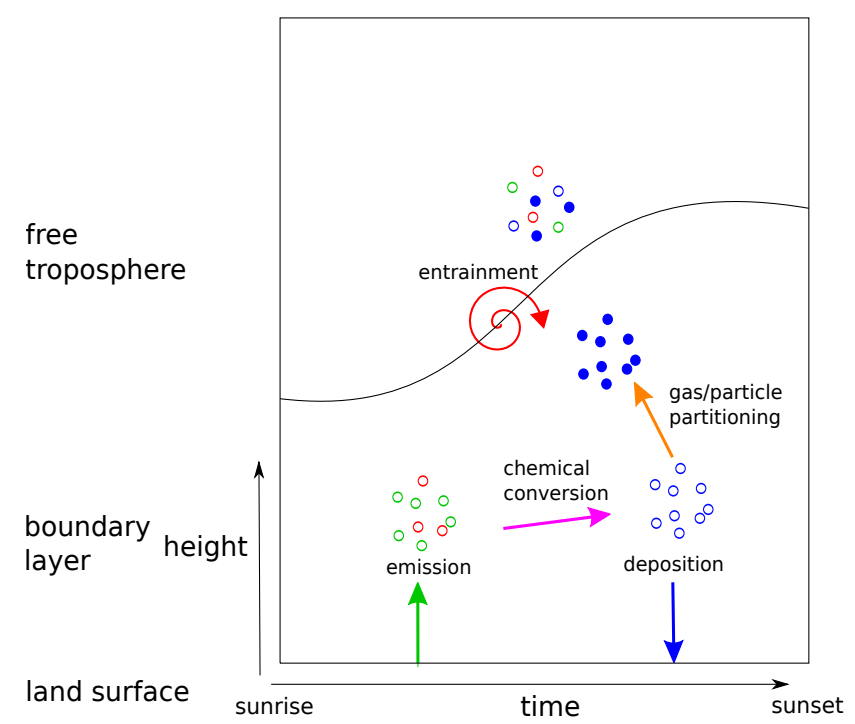

Figure 3. Processes relevant to evolution of species concentrations in the boundary layer. Open and closed circles depict gas-phase and aerosol-phase species, respectively.

For the implementation of MXL, a generic 1-D base model is created in MESSy, called VERTICO. VERTICO contains calls to modules for time and tracer management, the time loop which integrates the model equations and in VERTICO tracer concentrations are updated each time step, combining the tracer tendencies from each active submodel. It is de facto a 3-D base model in which the horizontal resolution has been reduced to a single grid box, to facilitate the submodel coupling within the MESSy framework. This also facilitates the possible development of a column model that includes more vertical levels in both boundary layer and free troposphere.

The current implementation of VERTICO consists of two domains (see Fig. 3): the lower one represents the well-mixed boundary layer during daytime, as represented by the MXL equations, and the upper box contains a simplified description of the free troposphere on top of the ABL. The FT is represented as a well-mixed box in which only chemistry and aerosol partitioning takes place. We have fixed the top of the FT to $10 \mathrm{~km}$, so changes in the ABL height only slightly influence the volume of the FT box. FT values of temperature, moisture and pressure that are needed for the calculations of FT reaction rates are taken at the inversion. The prognostic equations for the $\mathrm{ABL}$ dynamics and the land surface scheme are integrated by an Euler forward solver.

\section{Coupling with other MESSy submodels}

Through the MESSy framework, three types of submodels are coupled: the first type are the generic submodels, which constitute the model infrastructure that is not directly related to actual physical processes, such as time, tracer and data management. The second type are the process submodels, which represent the individual processes that contribute to the evolution of chemical species in the ABL (see Eq. 24 and Fig. 4). Finally, there are diagnostic submodels, which are used when additional post-processing of simulation output is needed. Table 1 shows all generic, process and diagnostic submodels that are currently coupled to form MXL/MESSy, and their tasks. In principle, thanks to such an implementation, any MESSy submodel can be used in MXL/MESSy.

The modular nature of the MESSy interface allows full flexibility: processes can easily be switched on and off through switches in a namelist. Emission and deposition of species takes place only in the lower box, while chemistry and gas/particle partitioning take place in both ABL and FT. The chemical production and loss of a species is calculated in the MECCA submodel (Sander et al., 2011), which uses the Kinetic PreProcessor (KPP; Sandu and Sander, 2006) for the numerical integration of the chemical reaction mechanism. MECCA uses photolysis rates calculated by JVAL (Sander et al., 2014).

For the lower boundary conditions, there are two possibilities. On one hand, MXL/MESSy offers the possibility to use interactive emission (via the ONEMIS (Kerkweg et al., 2006b) and MEGAN (Guenther et al., 2006) submodels), dry deposition (DDEP; Kerkweg et al., 2006a) and land surface parametrizations (Sect. 2.7). In these submodels, land surface-ABL exchange is calculated as function of land surface and ABL characteristics, like stomatal resistance and air temperature. On the other hand, it is possible to prescribe emissions and surface heat fluxes following simplified functions for the users who like to keep full control over the boundary conditions of the model (Sect. 2.5). In that way, MXL/MESSy can for instance be used to evaluate the sensitivity of the chemistry in the ABL to uncertainties in emission estimates. Further, OFFEMIS (Kerkweg et al., 2006b) allows for the extraction of emission time series from an emission database, which is read by IMPORT. Additionally, the organic aerosol submodel ORACLE (Tsimpidi et al., 2014), allows for the representation of the organic aerosol composition and evolution.

\section{DOMINO case study}

To evaluate MXL/MESSy, we revisited the case study of Van Stratum et al. (2012), which is based on observations from the DOMINO campaign in the south of Spain. Van Stratum et al. (2012) selected one day from this campaign, 23 November 2008, as a case study for disentangling ABL dynamics and chemistry. On this particular day, the influence of synoptic scale flows on the ABL dynamics was relatively small, there were no clouds, and wind speeds and background pollution levels were low. This assures that local processes (ABL dynamics, chemistry, emission and deposition) were the main drivers of the observed chemistry. Moreover, this day was during an intensive observation period, assuring 


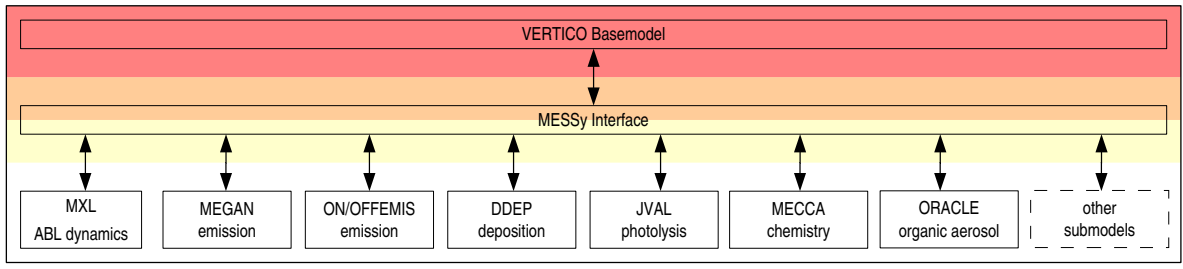

Figure 4. Scheme of the implementation of the VERTICO base model in the MESSy structure and the coupling to the MXL and other submodels through the MESSy interface.
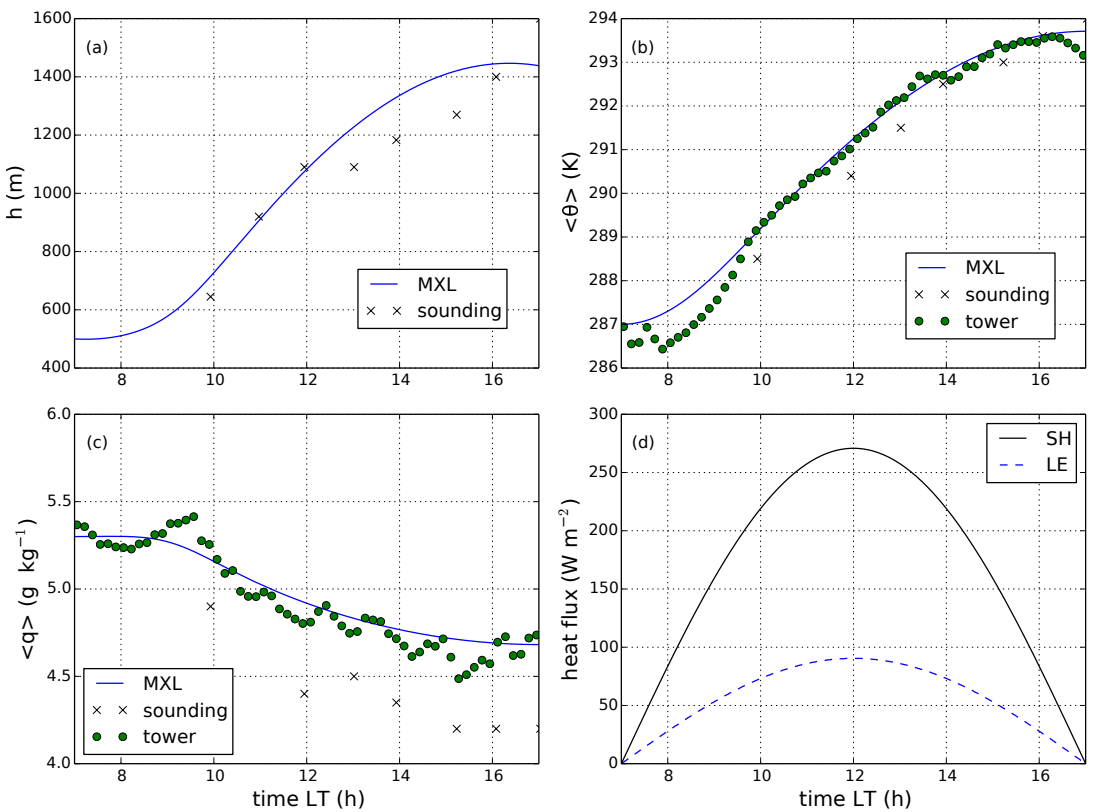

Figure 5. Diurnal evolution of observed and modelled (a) mixed-layer height $(h)$, (b) mixed-layer potential temperature $(\theta)$, (c) mixed-layer specific humidity $(q)$ and (d) prescribed sensible (SH) and latent (LE) heat fluxes.

that both ABL dynamics and chemistry were well characterized by observations.

MXL/MESSy, with initial conditions as in Table A1, represents the dynamics of the boundary layer well, as compared to observations from a tower and radio soundings (Fig. 5). Since the equations and the initial and boundary conditions are equal to those of Van Stratum et al. (2012), the dynamics of $\langle\theta\rangle,\langle q\rangle$ and $h$ are identical to those shown in their Fig. 3. As a result of the positive heat fluxes (Fig. 5d), the initial potential temperature inversion is broken after 09:00 LT, and the boundary layer starts to grow rapidly. During this period of strong ABL growth, air from the FT is entrained, which causes (1) a strong increase in $\langle\theta\rangle$, since warm air from the FT is entrained and (2) a decrease in $\langle q\rangle$ despite the positive latent heat flux (see Table A1), since dry air from the FT is entrained into the ABL. After 13:00 LT, the ABL growth slows down, and the effect of entrainment on scalars and chemical species becomes smaller. The correct representation of the boundary layer dynamics ensures that we also sim- ulate the effect of ABL dynamics on the evolution of chemical species well (through $h$ and $w_{\mathrm{e}}$ in Eqs. 24 and 25).

Figure 6 shows the diurnal evolution of several gas-phase chemical species, from measurements and from three model runs:

- the MXL/MESSy code with MIM2 chemistry (Taraborrelli et al., 2009), with initial conditions as in Van Stratum et al. (2012) (SameIC),

- the MXL/MESSy code with MIM2 chemistry (Taraborrelli et al., 2009), with initial conditions that gave the best fit with the measurements (BestFit),

- the MXLCH code as in Van Stratum et al. (2012).

The MXL/MESSy SameIC and MXLCH simulations were performed with identical initial conditions as listed in $\mathrm{Ta}$ ble A2. In the MXL/MESSy SameIC run we overestimate $\mathrm{NO}, \mathrm{NO}_{2}$ and isoprene, and underestimate $\mathrm{O}_{3}, \mathrm{HO}_{2}$ and $\mathrm{H}_{2} \mathrm{O}_{2}$. However, these results are influenced by the surface fluxes (emission and deposition) and the mixing ratios in the 

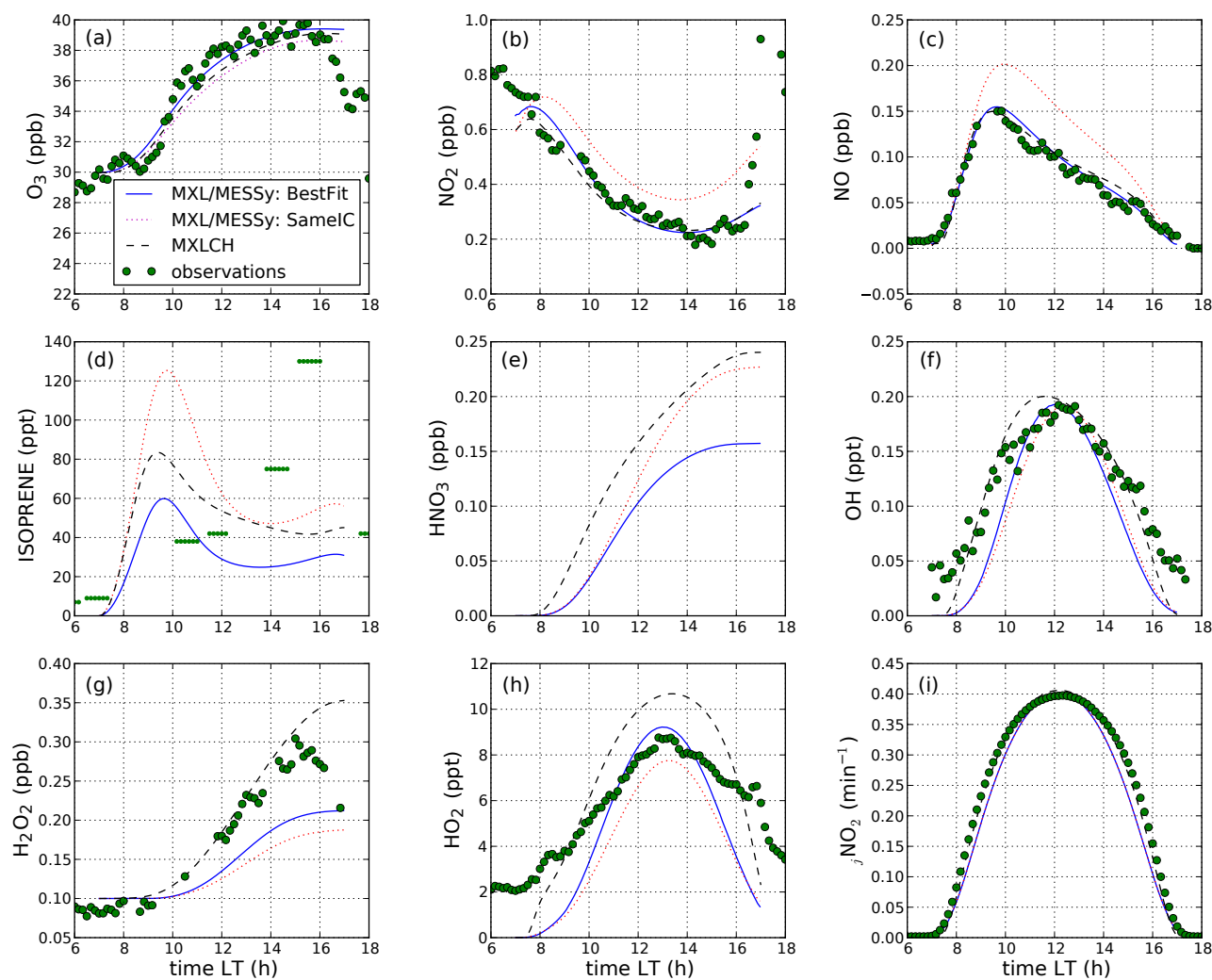

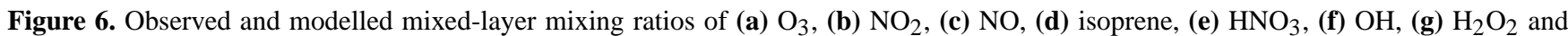
(h) $\mathrm{HO}_{2}$ and (i) $\mathrm{NO}_{2}$ photolysis rate for the DOMINO case, comparing MXL/MESSy and MIM2 chemistry with MXLCH and reduced chemistry. Results for both the SameIC and the BestFit runs with MXL/MESSy are shown.

FT of several species. Since these were not measured, this gives us some degrees of freedom to adjust them, within realistic bounds, to obtain an improved fit of MXL/MESSy with the observations.

Figure 6 also shows the MXL/MESSy BestFit results (with initial conditions as in Table A2). It shows that MXL/MESSy with the MIM2 chemical mechanism is able to reproduce the diurnal dynamics of the main gas-phase chemical species well. While it reproduces the timing and peak values of $\mathrm{OH}$ and $\mathrm{HO}_{2}$ well, the mixing ratios of both radicals are underestimated in the early morning and late afternoon. Also, $\mathrm{H}_{2} \mathrm{O}_{2}$ is underestimated from 10:00 LT to the late afternoon, which is related to the underestimation of $\mathrm{HO}_{2}$.

For this case study under conditions of low $\mathrm{NO}_{\mathrm{x}}$ and isoprene concentrations, MXL/MESSy with MIM2 chemistry and MXLCH with its reduced chemical scheme perform equally well, given the degrees of freedom available to tune the boundary conditions for the chemical species for each of these chemical schemes.

To give more insight in the diurnal evolution of chemical species, it is useful to analyse the contributions of the different processes to the total tendency (Eq. 24). The modular nature of MXL/MESSy facilitates the evaluation of the con- tributions of the individual processes, thanks to the diagnostic tools present in the MESSy framework.

In Fig. 7, an example is shown for $\mathrm{O}_{3}$, based on the optimally tuned (BestFit) simulation. The upper panel shows how the total $\mathrm{O}_{3}$ tendency is built up from the contributions of chemistry, entrainment and dry deposition (although the latter is set to zero), and the lower panel shows the chemistry term and how gas-phase and photolysis reactions contribute to the loss and production of ozone in the ABL. The contribution of entrainment to the $\mathrm{O}_{3}$ budget is strongest during the morning when the ABL grows rapidly and a large quantity of ozone-rich air is mixed in into the ABL from the FT. Except for the early morning and late afternoon, the sum of the chemical production and destruction of $\mathrm{O}_{3}$ is positive, and the net $\mathrm{O}_{3}$ production peaks around noon when photochemistry is strongest. Note that while we chose to show total production and loss terms for $\mathrm{O}_{3}$ here, it is possible to split up these terms into the contributions of the individual reactions. 

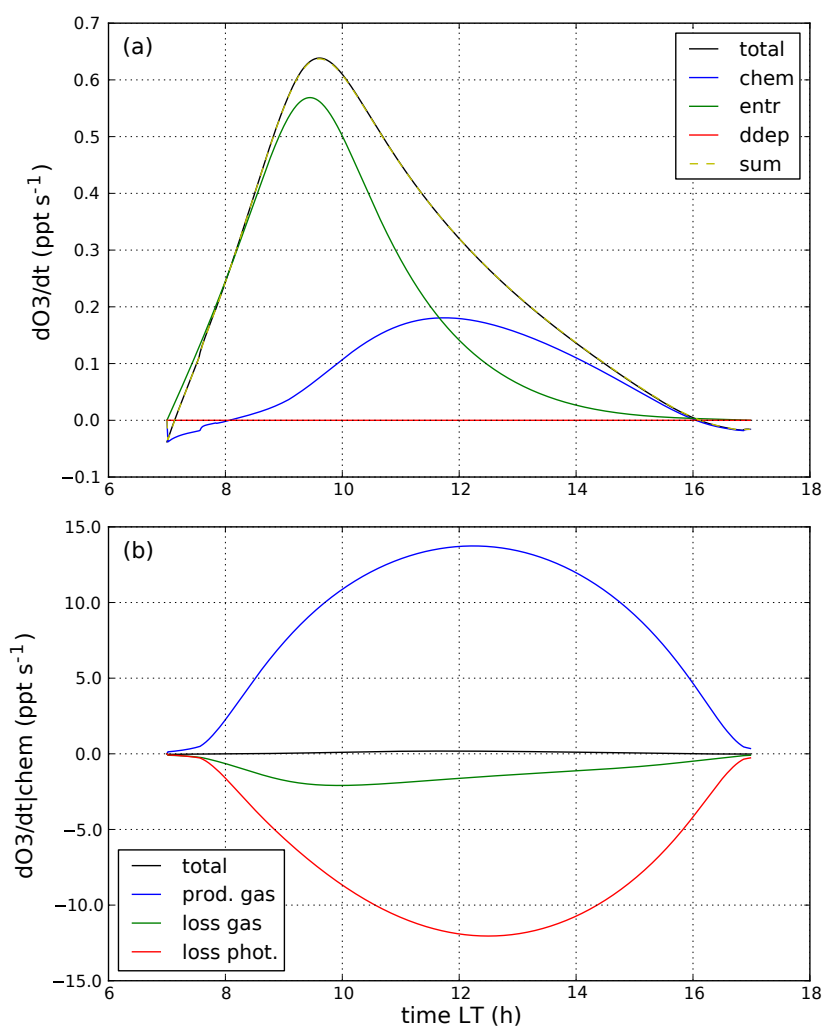

Figure 7. $\mathrm{O}_{3}$ budget for the DOMINO case showing the contributions of (a) the processes entrainment, chemistry and dry deposition and (b) the chemical production and loss with the chemical loss split up in a gas-phase destruction and a photolysis term.

\section{Summary}

We have implemented the MXL model as a new submodel in MESSy, in order to represent the diurnal dynamics of the atmospheric boundary layer and their effect on atmospheric chemistry. The comprehensiveness of MXL/MESSy in representing the processes relevant to atmospheric chemistry in the convective boundary layer, while keeping computational requirements low, makes it an ideal tool for applications in atmospheric chemistry that ask for systematic sensitivity analyses. These include the interpretation of observations from field campaigns and the evaluation of new process parametrizations under ambient conditions, as well as theoretical studies on the coupled land surface-boundary layeratmospheric chemistry system. Expansion of the model with additional relevant MESSy submodels and conversion into a multi-layer column model is planned for the future: e.g. including the surface layer, entrainment zone, accounting for imperfect mixing in ABL (e.g. due to clouds, aerosol layers) and the stable nocturnal boundary layer. 


\section{Appendix A: Initial and boundary conditions}

Table A1. The initial and boundary conditions in the atmospheric boundary layer (ABL) and free troposphere (FT) as used in MXL/MESSy and MXLCH. All initial conditions are imposed at 07:00 LT. $t$ is the time elapsed since the start of the simulation (s) and $t_{\mathrm{d}}$ the length of the simulation (s). The subscripts $\mathrm{s}$ and $\mathrm{e}$ indicate values at the surface and the entrainment zone, respectively.

\begin{tabular}{|c|c|}
\hline Property & Value \\
\hline $\begin{array}{l}\text { Initial ABL height } \\
h(\mathrm{~m})\end{array}$ & 500 \\
\hline $\begin{array}{l}\text { Subsidence rate } \\
\omega\left(\mathrm{s}^{-1}\right)\end{array}$ & $5 \times 10^{-6}$ \\
\hline $\begin{array}{l}\text { Surface sensible heat flux } \\
\frac{w^{\prime} \theta^{\prime}}{\mathrm{s}}\left(\mathrm{Km} \mathrm{s}^{-1}\right)\end{array}$ & $0.22 \sin \left(\pi t / t_{\mathrm{d}}\right)$ \\
\hline $\begin{array}{l}\text { Entrainment/surface heat flux ratio } \\
\beta=-\overline{w^{\prime} \theta^{\prime}}{ }_{\mathrm{e}} / \overline{w^{\prime} \theta^{\prime}}{ }_{\mathrm{S}} \text { (dimensionless) }\end{array}$ & 0.2 \\
\hline $\begin{array}{l}\text { Initial ABL potential temperature } \\
\langle\theta\rangle(\mathrm{K})\end{array}$ & 287 \\
\hline $\begin{array}{l}\text { Initial FT potential temperature } \\
\theta_{\mathrm{FT}}(\mathrm{K})\end{array}$ & 288.5 \\
\hline $\begin{array}{l}\text { Potential temperature lapse rate FT } \\
\gamma_{\theta}\left(\mathrm{Km}^{-1}\right)\end{array}$ & 0.006 \\
\hline $\begin{array}{l}\text { Surface latent heat flux } \\
\frac{w^{\prime} q^{\prime}}{\mathrm{s}}\left(\mathrm{g} \mathrm{kg}^{-1} \mathrm{~ms}^{-1}\right)\end{array}$ & $0.03 \sin \left(\pi t / t_{\mathrm{d}}\right)$ \\
\hline $\begin{array}{l}\text { Initial ABL specific humidity } \\
\langle q\rangle\left(\mathrm{g} \mathrm{kg}^{-1}\right)\end{array}$ & 5.3 \\
\hline $\begin{array}{l}\text { Initial FT specific humidity } \\
q_{\mathrm{FT}}\left(\mathrm{g} \mathrm{kg}^{-1}\right)\end{array}$ & 4.5 \\
\hline $\begin{array}{l}\text { Specific humidity lapse rate FT } \\
\gamma_{q}\left(\mathrm{~g} \mathrm{~kg}^{-1} \mathrm{~m}^{-1}\right)\end{array}$ & -0.0012 \\
\hline
\end{tabular}

Table A2. Initial mixing ratio in ABL and FT, and surface emission fluxes of the reactants for the different runs in MXL/MESSy and MXLCH. Species in the reaction mechanism that are not included in this table have an initial concentration of zero and no surface emissions. For $\mathrm{O}_{2}$ and $\mathrm{N}_{2}$ we have imposed the values $2 \times 10^{8}$ and $8 \times 10^{8} \mathrm{ppb}$, respectively.

\begin{tabular}{lccccccc}
\hline & $\mathrm{O}_{3}$ & $\mathrm{NO}$ & $\mathrm{NO}_{2}$ & $\mathrm{ISO}$ & $\mathrm{CH}_{4}$ & $\mathrm{CO}$ & $\mathrm{H}_{2} \mathrm{O}_{2}$ \\
\hline Van Stratum et al. (2012) & & & & & & & \\
Initial mixing ratio (ppb) & 30.0 & 0.0 & 0.6 & 0.0 & 1724.0 & 105.0 & 0.1 \\
ABL & 39.0 & 0.0 & 0.0 & 0.0 & 1724.0 & 105.0 & 0.1 \\
FT & 0.0 & 0.13 & 0.0 & $0.30 \sin \left(\frac{\pi t}{t_{\mathrm{d}}}\right)$ & 0.0 & 0.0 & 0.0 \\
Surface emission flux (mg m & $\left.-2 \mathrm{~h}^{-1}\right)$ & & & & & \\
\hline BestFit MXL/MESSy & & & & & & & \\
Initial mixing ratio (ppb) & 30.0 & 0.008 & 0.65 & 0.0 & 1724.0 & 105.0 & 0.1 \\
ABL & 41.0 & 0.0 & 0.0 & 0.0 & 1724.0 & 105.0 & 0.1 \\
FT & 0.0 & 0.07 & 0.0 & $0.15 \sin \left(\frac{\pi t}{t_{\mathrm{d}}}\right)$ & 0.0 & 0.0 & 0.0 \\
Surface emission flux (mg m & & & & & & & \\
\end{tabular}




\section{Appendix B: List of abbreviations}

Table B1. List of acronyms used in this work.

\begin{tabular}{ll}
\hline ABL & Atmospheric Boundary Layer \\
FT & Free Troposphere \\
KPP & Kinetic PreProcessor \\
LT & Local Time \\
MESSy & Modular Earth Submodel System \\
MIM2 & Mainz Isoprene Mechanism, version 2 \\
MXL & MiXed Layer model \\
MXLCH & MXL-CHemistry \\
UTC & Universal Time Coordinate \\
VERTICO & VERTICal COlumn \\
ZOJ & Zero-Order Jump closure \\
\hline
\end{tabular}

Table B2. List of variables and constants used in this work.

\begin{tabular}{|c|c|c|}
\hline Symbol & Unit & Description \\
\hline$a$ & - & Clapp-Hornberger retention curve parameter \\
\hline $\operatorname{adv}_{q}$ & $\mathrm{~g} \mathrm{~kg}^{-1} \mathrm{~s}^{-1}$ & Moisture advection \\
\hline $\operatorname{adv}_{\theta}$ & $\mathrm{Ks}^{-1}$ & Heat advection \\
\hline$b$ & - & Clapp-Hornberger retention curve parameter \\
\hline$C$ & $\mathrm{ppb}$ & Mixing ratio generic chemical species \\
\hline$\langle C\rangle$ & $\mathrm{ppb}$ & Mixed-layer mixing ratio generic chemical species \\
\hline$C_{\mathrm{FT}}$ & $\mathrm{ppb}$ & Mixing ratio of species $C$ in the FT \\
\hline$C_{\mathrm{H}}$ & - & Drag coefficient for heat \\
\hline$c_{\text {liq }}$ & - & Fraction of the vegetated area that contains liquid water \\
\hline$C_{\mathrm{M}}$ & - & Drag coefficient for momentum \\
\hline$c_{p}$ & $\mathrm{~J} \mathrm{~kg}^{-1} \mathrm{~K}^{-1}$ & Specific heat of air \\
\hline$C_{\mathrm{T}}$ & $\mathrm{K} \mathrm{m}^{2} \mathrm{~J}^{-1}$ & Surface soil/vegetation heat capacity \\
\hline$C_{\mathrm{T}, \mathrm{sat}}$ & $\mathrm{Km}^{2} \mathrm{~J}^{-1}$ & Surface soil/vegetation heat capacity at saturation \\
\hline$c_{\mathrm{veg}}$ & - & Fraction of the total area that is covered by vegetation \\
\hline$C_{1}$ & - & Coefficient related to the Clapp-Hornberger parametrization \\
\hline$C_{1, \text { sat }}$ & - & Coefficient force term moisture \\
\hline$C_{2}$ & - & Coefficient related to the Clapp-Hornberger parametrization \\
\hline$C_{2, \text { ref }}$ & - & Coefficient restore term moisture \\
\hline$d$ & - & Julian day \\
\hline$d_{\mathrm{r}}$ & - & Day of the summer solstice \\
\hline$d_{\mathrm{y}}$ & - & Number of days in a year \\
\hline$d_{1}$ & $\mathrm{~m}$ & Normalization depth \\
\hline$f_{\mathrm{c}}$ & $\mathrm{s}^{-1}$ & Coriolis parameter \\
\hline$F_{C}$ & $\mathrm{ppbms}^{-1}$ & (Maximum) daily emission flux of species $C$ \\
\hline $\mathrm{G}$ & $\mathrm{W} \mathrm{m}^{-2}$ & Soil heat flux \\
\hline$g_{\mathrm{D}}$ & $\mathrm{Pa}^{-1}$ & Correction factor for vapour pressure deficit \\
\hline$h$ & $\mathrm{~m}$ & ABL height \\
\hline$L$ & $\mathrm{~m}$ & Monin-Obukhov length \\
\hline LAI & - & Leaf area index of the vegetated fraction \\
\hline LE & $\mathrm{W} \mathrm{m}^{-2}$ & Latent heat flux / total evapotranspiration \\
\hline $\mathrm{LE}_{\text {liq }}$ & $\mathrm{W} \mathrm{m}^{-2}$ & Evaporation of liquid water \\
\hline $\mathrm{LE}_{\text {soil }}$ & $\mathrm{W} \mathrm{m}^{-2}$ & Evaporation from the soil \\
\hline $\mathrm{LE}_{\mathrm{veg}}$ & $\mathrm{W} \mathrm{m}^{-2}$ & Transpiration from vegetation \\
\hline$L_{\text {in }}$ & $\mathrm{W} \mathrm{m}^{-2}$ & Incoming long wave radiation \\
\hline$L_{\text {out }}$ & $\mathrm{W} \mathrm{m}^{-2}$ & Outgoing component radiation \\
\hline
\end{tabular}


Table B2. Continued.

\begin{tabular}{|c|c|c|}
\hline Symbol & Unit & Description \\
\hline$L_{\mathrm{V}}$ & $\mathrm{J} \mathrm{kg}^{-1}$ & Latent heat of vaporization \\
\hline$p$ & - & Clapp-Hornberger retention curve parameter \\
\hline$q$ & $\mathrm{~g} \mathrm{~kg}^{-1}$ & Specific humidity \\
\hline$\langle q\rangle$ & $\mathrm{g} \mathrm{kg}^{-1}$ & Mixed-layer specific humidity \\
\hline$q_{\mathrm{FT}}$ & $\mathrm{g} \mathrm{kg}^{-1}$ & FT specific humidity \\
\hline$q_{\text {sat }}(T)$ & $\mathrm{g} \mathrm{kg}^{-1}$ & Saturated specific humidity at temperature $T$ \\
\hline$q_{\text {sat }}\left(T_{\mathrm{S}}\right)$ & $\mathrm{g} \mathrm{kg}^{-1}$ & Saturated specific humidity inside the canopy \\
\hline$r_{\mathrm{a}}$ & $\mathrm{sm}^{-1}$ & Aerodynamic resistance \\
\hline$R i_{\mathrm{B}}$ & - & Bulk Richardson number \\
\hline$R_{\mathrm{n}}$ & $\mathrm{W} \mathrm{m}^{-2}$ & Net radiation at the surface \\
\hline$r_{\mathrm{S}}$ & $\mathrm{sm}^{-1}$ & Surface resistance \\
\hline$r_{\text {soil }}$ & $\mathrm{sm}^{-1}$ & Soil resistance \\
\hline$r_{\mathrm{s}, \min }$ & $\mathrm{sm}^{-1}$ & Minimum surface resistance \\
\hline$r_{\mathrm{veg}}$ & $\mathrm{s} \mathrm{m}^{-1}$ & Vegetation resistance \\
\hline$S_{C}$ & $\operatorname{ppbs}^{-1}$ & Chemical transformation of species $C$ \\
\hline $\mathrm{SH}$ & $\mathrm{W} \mathrm{m}^{-2}$ & Sensible heat flux \\
\hline$S_{\text {in }}$ & $\mathrm{W} \mathrm{m}^{-2}$ & Incoming short wave radiation \\
\hline$S_{\text {out }}$ & $\mathrm{W} \mathrm{m}^{-2}$ & Outgoing short wave radiation \\
\hline$S_{\mathrm{O}}$ & $\mathrm{W} \mathrm{m}^{-2}$ & Solar irradiance at the top of the atmosphere \\
\hline$t$ & $\mathrm{~S}$ & Time of day \\
\hline$t_{\mathrm{d}}$ & $\mathrm{s}$ & Day length \\
\hline$T_{\mathrm{r}}$ & - & Net sky transmissivity \\
\hline$T_{\mathrm{S}}$ & $\mathrm{K}$ & Surface temperature \\
\hline$T_{\mathrm{s} 1}$ & $\mathrm{~K}$ & Temperature at the top of the surface layer \\
\hline$T_{\text {soil1 }}$ & $\mathrm{K}$ & Temperature of top soil layer \\
\hline$T_{\text {soil2 }}$ & $\mathrm{K}$ & Temperature of deeper soil layer \\
\hline$t_{\mathrm{UTC}}$ & $\mathrm{h}$ & Time of day in UTC \\
\hline$U$ & $\mathrm{~ms}^{-1}$ & Horizontal wind speed \\
\hline$\langle u\rangle$ & $\mathrm{ms}^{-1}$ & Mixed-layer wind velocity in $\mathrm{x}$-direction \\
\hline$\langle U\rangle$ & $\mathrm{ms}^{-1}$ & Mixed-layer wind speed \\
\hline$\overline{u^{\prime} w^{\prime}} \mathrm{e}$ & $\mathrm{ms}^{-1} \mathrm{~ms}^{-1}$ & Entrainment momentum flux in $\mathrm{x}$-direction \\
\hline$\overline{u^{\prime} w_{\mathrm{s}}^{\prime}}$ & $\mathrm{ms}^{-1} \mathrm{~ms}^{-1}$ & Surface momentum flux in $\mathrm{x}$-direction \\
\hline$u_{*}$ & $\mathrm{~ms}^{-1}$ & Friction velocity \\
\hline$\langle v\rangle$ & $\mathrm{ms}^{-1}$ & Mixed-layer wind velocity in y-direction \\
\hline VPD & $\mathrm{Pa}$ & Vapour pressure deficit \\
\hline$\overline{v^{\prime} w^{\prime}} \mathrm{e}$ & $\mathrm{ms}^{-1} \mathrm{~ms}^{-1}$ & Entrainment momentum flux in $y$-direction \\
\hline$\overline{v^{\prime} w_{\mathrm{s}}^{\prime}}$ & $\mathrm{ms}^{-1} \mathrm{~ms}^{-1}$ & Surface momentum flux in y-direction \\
\hline$w$ & $\mathrm{~m}^{3} \mathrm{~m}^{-3}$ & Soil volumetric water content \\
\hline$w_{\mathrm{e}}$ & $\mathrm{ms}^{-1}$ & Entrainment velocity \\
\hline$w_{\mathrm{fc}}$ & $\mathrm{m}^{3} \mathrm{~m}^{-3}$ & Volumetric soil moisture at field capacity \\
\hline$w_{1}$ & $\mathrm{~ms}^{-1}$ & Large-scale vertical velocity \\
\hline$W_{1}$ & $\mathrm{~m}$ & Actual water depth on the leaf \\
\hline$W_{\max }$ & $\mathrm{m}$ & Representative depth of a water layer on a leaf \\
\hline$w_{\text {sat }}$ & $\mathrm{m}^{3} \mathrm{~m}^{-3}$ & Saturated volumetric water content \\
\hline$w_{\text {wilt }}$ & $\mathrm{m}^{3} \mathrm{~m}^{-3}$ & Volumetric soil moisture at wilting point \\
\hline$w_{1}$ & $\mathrm{~m}^{3} \mathrm{~m}^{-3}$ & Volumetric water content of top soil layer \\
\hline$w_{1, \mathrm{eq}}$ & $\mathrm{m}^{3} \mathrm{~m}^{-3}$ & Soil water content in equilibrium \\
\hline$w_{2}$ & $\mathrm{~m}^{3} \mathrm{~m}^{-3}$ & Volumetric water content of deeper soil layer \\
\hline
\end{tabular}


Table B2. Continued.

\begin{tabular}{|c|c|c|}
\hline Symbol & Unit & Description \\
\hline$w_{*}$ & $\mathrm{~ms}^{-1}$ & Free convection scaling velocity \\
\hline$\overline{w^{\prime} C^{\prime}} \mathrm{e}$ & $\mathrm{ppbms}^{-1}$ & Entrainment flux of species $C$ \\
\hline$\overline{w^{\prime} C^{\prime}}{ }_{\mathrm{s}}$ & $\mathrm{ppbms}^{-1}$ & Surface flux of species $C$ \\
\hline$\overline{w^{\prime} q_{\mathrm{e}}^{\prime}}$ & $\mathrm{g} \mathrm{kg}^{-1} \mathrm{~ms}^{-1}$ & Entrainment specific moisture flux \\
\hline$\overline{w^{\prime} q^{\prime}}{ }_{\mathrm{s}}$ & $\mathrm{g} \mathrm{kg}^{-1} \mathrm{~ms}^{-1}$ & Surface specific moisture flux \\
\hline$\overline{w^{\prime} \theta_{v \mathrm{e}}^{\prime}}$ & $\mathrm{Kms}^{-1}$ & Entrainment buoyancy flux \\
\hline$\overline{w^{\prime} \theta_{v \mathrm{~s}}^{\prime}}$ & $\mathrm{Kms}^{-1}$ & Surface buoyancy flux \\
\hline${\overline{w^{\prime} \theta^{\prime}}}_{\mathrm{e}}$ & $\mathrm{Kms}^{-1}$ & Entrainment kinematic heat flux \\
\hline$\overline{w^{\prime} \theta^{\prime}}{ }_{\mathrm{s}}$ & $\mathrm{Kms}^{-1}$ & Surface kinematic heat flux \\
\hline$z_{\mathrm{s} 1}$ & $\mathrm{~m}$ & Height of the atmospheric surface layer \\
\hline$z_{0 \mathrm{~h}}$ & $\mathrm{~m}$ & Roughness length for heat \\
\hline$z_{0 \mathrm{~m}}$ & $\mathrm{~m}$ & Roughness length for momentum \\
\hline$\alpha$ & - & Surface albedo \\
\hline$\beta$ & - & Entrainment/surface heat flux ratio \\
\hline$\gamma_{q}$ & $\mathrm{~g} \mathrm{~kg}^{-1} \mathrm{~m}^{-1}$ & Lapse rate of $q$ in the FT \\
\hline$\gamma_{u}$ & $\mathrm{~ms}^{-1} \mathrm{~m}^{-1}$ & Lapse rate of $u$ in the FT \\
\hline$\gamma_{v}$ & $\mathrm{~ms}^{-1} \mathrm{~m}^{-1}$ & Lapse rate of $v$ in the FT \\
\hline$\gamma_{\theta}$ & $\mathrm{Km}^{-1}$ & Lapse rate of $\theta$ in the FT \\
\hline$\Delta C$ & $\mathrm{ppb}$ & Jump of species $C$ \\
\hline$\Delta q$ & $\mathrm{~g} \mathrm{~kg}^{-1}$ & Specific humidity jump \\
\hline$\delta_{\mathrm{S}}$ & $\mathrm{rad}$ & Solar declination \\
\hline$\Delta u$ & $\mathrm{~ms}^{-1}$ & Jump of $u$ \\
\hline$\Delta v$ & $\mathrm{~ms}^{-1}$ & Jump of $v$ \\
\hline$\Delta \theta$ & $\mathrm{K}$ & Potential temperature jump \\
\hline$\Delta \theta_{\mathrm{V}}$ & $\mathrm{K}$ & Virtual potential temperature jump \\
\hline$\epsilon_{\mathrm{a}}$ & - & Atmospheric emissivity \\
\hline$\epsilon_{\mathrm{s}}$ & - & Surface emissivity \\
\hline$\theta$ & $\mathrm{K}$ & Potential temperature \\
\hline$\langle\theta\rangle$ & $\mathrm{K}$ & Mixed-layer potential temperature \\
\hline$\theta_{\mathrm{FT}}$ & $\mathrm{K}$ & FT potential temperatures \\
\hline$\theta_{\mathrm{S}}$ & $\mathrm{K}$ & Potential temperatures at the surface \\
\hline$\theta_{\mathrm{V}}$ & $\mathrm{K}$ & Virtual potential temperature \\
\hline$\left\langle\theta_{v}\right\rangle$ & $\mathrm{K}$ & Mixed-layer virtual potential temperature \\
\hline$\theta_{\mathrm{v}, \mathrm{s}}$ & $\mathrm{K}$ & Surface virtual potential temperature \\
\hline$\kappa$ & - & von Kármán constant \\
\hline$\Lambda$ & $\mathrm{W} \mathrm{m}^{-2} \mathrm{~K}^{-1}$ & Thermal conductivity of the skin layer \\
\hline$\lambda_{\mathrm{e}}$ & $\operatorname{rad}$ & Longitude \\
\hline$\rho$ & $\mathrm{kg} \mathrm{m}^{-3}$ & Density of air \\
\hline$\rho_{\mathrm{W}}$ & $\mathrm{kg} \mathrm{m}^{-3}$ & Density of water \\
\hline$\sigma_{\mathrm{SB}}$ & $\mathrm{W} \mathrm{m}^{-2} \mathrm{~K}^{-4}$ & Stefan-Boltzmann constant \\
\hline$\tau$ & $\mathrm{s}$ & Time constant of one day \\
\hline$\phi$ & $\mathrm{rad}$ & Latitude \\
\hline$\Phi_{\mathrm{r}}$ & $\mathrm{rad}$ & Tilt of the Earth's axis relative to the elliptic \\
\hline$\Psi$ & $\mathrm{rad}$ & Solar elevation angle \\
\hline$\Psi_{\mathrm{H}}$ & - & Integrated stability function for heat \\
\hline$\Psi_{\mathrm{M}}$ & - & Integrated stability function for momentum \\
\hline$\omega$ & $s^{-1}$ & Subsidence rate \\
\hline
\end{tabular}




\section{Code availability}

MXL/MESSy is part of the Modular Earth Submodel System (MESSy), which is continuously developed and applied by a consortium of institutions. The usage of MESSy and access to the source code is licensed to all affiliates of institutions which are members of the MESSy Consortium. Institutions can be a member of the MESSy Consortium by signing the MESSy Memorandum of Understanding. More information can be found on the MESSy Consortium website (www.messy-interface.org).

\section{The Supplement related to this article is available online at doi:10.5194/gmd-8-453-2015-supplement.}

Acknowledgements. The authors thank Jordi Vilà for his useful comments on the DOMINO data and on the manuscript, Rolf Sander and Sergey Gromov for their helpful discussions on the implementation of MXL in MESSy and Chiel van Heerwaarden for providing the land surface scheme equations.

The service charges for this open-access publication have been covered by the Max Planck Society.

Edited by: J. Williams

\section{References}

Beljaars, A. C. M.: Numerical Schemes for Parametrizations, ECMWF Seminar on Numerical Methods in Atmospheric Models, Reading, UK, 9-13 September 1991, 1-42, 1991.

Butler, T. M., Taraborrelli, D., Brühl, C., Fischer, H., Harder, H., Martinez, M., Williams, J., Lawrence, M. G., and Lelieveld, J.: Improved simulation of isoprene oxidation chemistry with the ECHAM5/MESSy chemistry-climate model: lessons from the GABRIEL airborne field campaign, Atmos. Chem. Phys., 8, 4529-4546, doi:10.5194/acp-8-4529-2008, 2008.

Clapp, R. B. and Hornberger, G. M.: Empirical equations for some soil hydraulic properties, Water Resour. Res., 14, 601-604, doi:10.1029/WR014i004p00601, 1978.

Conzemius, R. J. and Fedorovich, E.: Dynamics of sheared convective boundary layer entrainment. Part II: Evaluation of bulk model predictions of entrainment flux, J. Atmos. Sci., 63, 11791199, doi:10.1175/JAS3696.1, 2006.

Duynkerke, P. G.: Radiation fog: a comparison of model simulation with detailed observations, Mon. Weather Rev., 119, 324-341, doi:10.1175/1520-0493(1991)119<0324:RFACOM>2.0.CO;2, 1991.

Guenther, A., Karl, T., Harley, P., Wiedinmyer, C., Palmer, P. I., and Geron, C.: Estimates of global terrestrial isoprene emissions using MEGAN (Model of Emissions of Gases and Aerosols from Nature), Atmos. Chem. Phys., 6, 3181-3210, doi:10.5194/acp-63181-2006, 2006.

Jacobs, C. M. J. and De Bruin, H. A. R.: The sensitivity of regional transpiration to land-surface characteristics: significance of feedback, J. Climate, 5, 683-698, doi:10.1175/15200442(1992)005<0683:TSORTT>2.0.CO;2, 1992.
Janssen, R. H. H., Vilà-Guerau de Arellano, J., Ganzeveld, L. N., Kabat, P., Jimenez, J. L., Farmer, D. K., van Heerwaarden, C. C., and Mammarella, I.: Combined effects of surface conditions, boundary layer dynamics and chemistry on diurnal SOA evolution, Atmos. Chem. Phys., 12, 6827-6843, doi:10.5194/acp-126827-2012, 2012.

Janssen, R. H. H., Vilà-Guerau de Arellano, J., Jimenez, J. L., Ganzeveld, L. N., Robinson, N. H., Allan, J. D., Coe, H., and Pugh, T. A. M.: Influence of boundary layer dynamics and isoprene chemistry on the organic aerosol budget in a tropical forest, J. Geophys. Res.-Atmos., 118, 9351-9366, doi:10.1002/jgrd.50672, 2013.

Jarvis, P. G.: The interpretation of the variations in leaf water potential and stomatal conductance found in canopies in the field, Philos. T. Roy. Soc. B, 273, 593-610, doi:10.1098/rstb.1976.0035, 1976.

Jöckel, P., Sander, R., Kerkweg, A., Tost, H., and Lelieveld, J.: Technical Note: The Modular Earth Submodel System (MESSy) - a new approach towards Earth System Modeling, Atmos. Chem. Phys., 5, 433-444, doi:10.5194/acp-5-433-2005, 2005.

Jöckel, P., Tost, H., Pozzer, A., Brühl, C., Buchholz, J., Ganzeveld, L., Hoor, P., Kerkweg, A., Lawrence, M. G., Sander, R., Steil, B., Stiller, G., Tanarhte, M., Taraborrelli, D., van Aardenne, J., and Lelieveld, J.: The atmospheric chemistry general circulation model ECHAM5/MESSy1: consistent simulation of ozone from the surface to the mesosphere, Atmos. Chem. Phys., 6, 50675104, doi:10.5194/acp-6-5067-2006, 2006.

Jöckel, P., Kerkweg, A., Buchholz-Dietsch, J., Tost, H., Sander, R., and Pozzer, A.: Technical Note: Coupling of chemical processes with the Modular Earth Submodel System (MESSy) submodel TRACER, Atmos. Chem. Phys., 8, 1677-1687, doi:10.5194/acp8-1677-2008, 2008.

Jöckel, P., Kerkweg, A., Pozzer, A., Sander, R., Tost, H., Riede, H., Baumgaertner, A., Gromov, S., and Kern, B.: Development cycle 2 of the Modular Earth Submodel System (MESSy2), Geosci. Model Dev., 3, 717-752, doi:10.5194/gmd-3-717-2010, 2010.

Kerkweg, A., Buchholz, J., Ganzeveld, L., Pozzer, A., Tost, H., and Jöckel, P.: Technical Note: An implementation of the dry removal processes DRY DEPosition and SEDImentation in the Modular Earth Submodel System (MESSy), Atmos. Chem. Phys., 6, 4617-4632, doi:10.5194/acp-6-4617-2006, 2006a.

Kerkweg, A., Sander, R., Tost, H., and Jöckel, P.: Technical note: Implementation of prescribed (OFFLEM), calculated (ONLEM), and pseudo-emissions (TNUDGE) of chemical species in the Modular Earth Submodel System (MESSy), Atmos. Chem. Phys., 6, 3603-3609, doi:10.5194/acp-6-3603-2006, $2006 \mathrm{~b}$.

Lilly, D. K.: Models of cloud-topped mixed layers under a strong inversion, Q. J. Roy. Meteor. Soc., 94, 292-309, doi:10.1002/qj.49709440106, 1968.

Monteith, J. L.: Evaporation and the environment, Sym. Soc. Exp. Biol., 19, 205-234, 1965.

Noilhan, J. and Planton, S.: A simple parameterization of land surface processes for meteorological models, Mon. Weather Rev., 117, 536-549, doi:10.1175/15200493(1989)117<0536:ASPOLS>2.0.CO;2, 1989.

Ouwersloot, H. G., Vilà-Guerau de Arellano, J., van Heerwaarden, C. C., Ganzeveld, L. N., Krol, M. C., and Lelieveld, J.: On the segregation of chemical species in a clear boundary layer over 
heterogeneous land surfaces, Atmos. Chem. Phys., 11, 1068110704, doi:10.5194/acp-11-10681-2011, 2011.

Ouwersloot, H. G., Vilà-Guerau de Arellano, J., Nölscher, A. C., Krol, M. C., Ganzeveld, L. N., Breitenberger, C., Mammarella, I., Williams, J., and Lelieveld, J.: Characterization of a boreal convective boundary layer and its impact on atmospheric chemistry during HUMPPA-COPEC-2010, Atmos. Chem. Phys., 12, 9335-9353, doi:10.5194/acp-12-9335-2012, 2012.

Pietersen, H., Vilà-Guerau de Arellano, J., Augustin, P., de Coster, O., Delbarre, H., Durand, P., Fourmentin, M., Gioli, B., Hartogensis, O., Lothon, M., Lohou, F., Pino, D., Ouwersloot, H. G., Reuder, J., and van de Boer, A.: Study of a prototypical convective boundary layer observed during BLLAST: contributions by large-scale forcings, Atmos. Chem. Phys. Discuss., 14, 1924719291, doi:10.5194/acpd-14-19247-2014, 2014.

Pino, D., Vilà-Guerau de Arellano, J., and Duynkerke, P. G.: The contribution of shear to the evolution of a convective boundary layer, J. Atmos. Sci., 60, 1913-1926, doi:10.1175/15200469(2003)060<1913:TCOSTT>2.0.CO;2, 2003.

Pino, D., Vilà-Guerau de Arellano, J., and Kim, S.-W.: Representing sheared convective boundary layer by zeroth- and first-orderjump mixed-layer models: large-eddy simulation verification, J. Appl. Meteorol. Clim., 45, 1224-1243, doi:10.1175/JAM2396.1, 2006

Pugh, T. A. M., MacKenzie, A. R., Hewitt, C. N., Langford, B., Edwards, P. M., Furneaux, K. L., Heard, D. E., Hopkins, J. R., Jones, C. E., Karunaharan, A., Lee, J., Mills, G., Misztal, P., Moller, S., Monks, P. S., and Whalley, L. K.: Simulating atmospheric composition over a South-East Asian tropical rainforest: performance of a chemistry box model, Atmos. Chem. Phys., 10, 279-298, doi:10.5194/acp-10-279-2010, 2010.

Pugh, T. A. M., MacKenzie, A. R., Langford, B., Nemitz, E., Misztal, P. K., and Hewitt, C. N.: The influence of small-scale variations in isoprene concentrations on atmospheric chemistry over a tropical rainforest, Atmos. Chem. Phys., 11, 4121-4134, doi:10.5194/acp-11-4121-2011, 2011.

Sander, R., Baumgaertner, A., Gromov, S., Harder, H., Jöckel, P., Kerkweg, A., Kubistin, D., Regelin, E., Riede, H., Sandu, A., Taraborrelli, D., Tost, H., and Xie, Z.-Q.: The atmospheric chemistry box model CAABA/MECCA-3.0, Geosci. Model Dev., 4, 373-380, doi:10.5194/gmd-4-373-2011, 2011.

Sander, R., Jöckel, P., Kirner, O., Kunert, A. T., Landgraf, J., and Pozzer, A.: The photolysis module JVAL-14, compatible with the MESSy standard, and the JVal PreProcessor (JVPP), Geosci. Model Dev., 7, 2653-2662, doi:10.5194/gmd-7-26532014, 2014.

Sandu, A. and Sander, R.: Technical note: Simulating chemical systems in Fortran90 and Matlab with the Kinetic PreProcessor KPP-2.1, Atmos. Chem. Phys., 6, 187-195, doi:10.5194/acp-6187-2006, 2006.

Stull, R. B.: An introduction to boundary layer meteorology, Kluwer Academic Publishers, Dordrecht, The Netherlands, 1988.

Taraborrelli, D., Lawrence, M. G., Butler, T. M., Sander, R., and Lelieveld, J.: Mainz Isoprene Mechanism 2 (MIM2): an isoprene oxidation mechanism for regional and global atmospheric modelling, Atmos. Chem. Phys., 9, 2751-2777, doi:10.5194/acp-92751-2009, 2009.
Tennekes, H.: A model for the dynamics of the inversion above a convective boundary layer, J. Atmos. Sci., 30, 558-567, doi:10.1175/1520-0469(1973)030<0558:AMFTDO>2.0.CO;2, 1973.

Tennekes, H. and Driedonks, A.: Basic entrainment equations for the atmospheric boundary layer, Bound.-Lay. Meteorol., 20, 515-531, doi:10.1007/BF00122299, 1981.

Tsimpidi, A. P., Karydis, V. A., Pozzer, A., Pandis, S. N., and Lelieveld, J.: ORACLE (v1.0): module to simulate the organic aerosol composition and evolution in the atmosphere, Geosci. Model Dev., 7, 3153-3172, doi:10.5194/gmd-7-31532014, 2014.

Van Heerwaarden, C. C.: Surface Evaporation and Water Vapor Transport in the Convective Boundary Layer, PhD thesis, Wageningen University, Wageningen, the Netherlands, 2011.

Van Heerwaarden, C. C., Vilà-Guerau de Arellano, J., Moene, A. F., and Holtslag, A. A. M.: Interactions between dry-air entrainment, surface evaporation and convective boundary-layer development, Q. J. Roy. Meteor. Soc., 135, 1277-1291, doi:10.1002/qj.431, 2009.

Van Heerwaarden, C. C., Vilà-Guerau de Arellano, J., Gounou, A., Guichard, F., and Couvreux, F.: Understanding the daily cycle of evapotranspiration: a method to quantify the influence of forcings and feedbacks, J. Hydrometeorol., 11, 1405-1422, doi:10.1175/2010JHM1272.1, 2010.

Van Stratum, B. J. H., Vilà-Guerau de Arellano, J., Ouwersloot, H. G., van den Dries, K., van Laar, T. W., Martinez, M., Lelieveld, J., Diesch, J.-M., Drewnick, F., Fischer, H., Hosaynali Beygi, Z., Harder, H., Regelin, E., Sinha, V., Adame, J. A., Sörgel, M., Sander, R., Bozem, H., Song, W., Williams, J., and Yassaa, N.: Case study of the diurnal variability of chemically active species with respect to boundary layer dynamics during DOMINO, Atmos. Chem. Phys., 12, 5329-5341, doi:10.5194/acp-12-53292012, 2012.

Vilà-Guerau de Arellano, J., van den Dries, K., and Pino, D.: On inferring isoprene emission surface flux from atmospheric boundary layer concentration measurements, Atmos. Chem. Phys., 9, 3629-3640, doi:10.5194/acp-9-3629-2009, 2009.

Vilà-Guerau de Arellano, J., Patton, E. G., Karl, T., Van den Dries, K., Barth, M. C., and Orlando, J. J.: The role of boundary layer dynamics on the diurnal evolution of isoprene and the hydroxyl radical over tropical forests, J. Geophys. Res., 116, D07304, doi:10.1029/2010JD014857, 2011.

Vilà-Guerau de Arellano, J., Van Heerwaarden, C. C., and Lelieveld, J.: Modelled suppression of boundary-layer clouds by plants in a $\mathrm{CO}_{2}$-rich atmosphere, Nat. Geosci., 5, 701-704, doi:10.1038/ngeo1554, 2012.

Vilà-Guerau de Arellano, J., Van Heerwaarden, C., Van Stratum, B., and Van den Dries, K.: Atmospheric Boundary Layer: Integrating Air Chemistry and Land Interactions, Cambridge University Press, Cambridge, UK, in press, 2015.

Vinuesa, J.-F. and Vilà-Guerau de Arellano, J.: Fluxes and (co)variances of reacting scalars in the convective boundary layer, Tellus B, 55, 935-949, doi:10.1046/j.1435-6935.2003.00073.x, 2003. 